\title{
OPEN The virome of German bats: comparing virus discovery approaches
}

\author{
Claudia Kohl ${ }^{1 凶}$, Annika Brinkmann ${ }^{1}$, Aleksandar Radonić2 ${ }^{2}$ Piotr Wojtek Dabrowski ${ }^{3}$, \\ Kristin Mühldorfer ${ }^{4}$, Andreas Nitsche ${ }^{1}$, Gudrun Wibbelt $\mathbb{1}^{4}$ \& Andreas Kurth ${ }^{1}$
}

Bats are known to be reservoirs of several highly pathogenic viruses. Hence, the interest in bat virus discovery has been increasing rapidly over the last decade. So far, most studies have focused on a single type of virus detection method, either $P C R$, virus isolation or virome sequencing. Here we present a comprehensive approach in virus discovery, using all three discovery methods on samples from the same bats. By family-specific PCR screening we found sequences of paramyxoviruses, adenoviruses, herpesviruses and one coronavirus. By cell culture we isolated a novel bat adenovirus and bat orthoreovirus. Virome sequencing revealed viral sequences of ten different virus families and orders: three bat nairoviruses, three phenuiviruses, one orbivirus, one rotavirus, one orthoreovirus, one mononegavirus, five parvoviruses, seven picornaviruses, three retroviruses, one totivirus and two thymoviruses were discovered. Of all viruses identified by family-specific PCR in the original samples, none was found by metagenomic sequencing. Vice versa, none of the viruses found by the metagenomic virome approach was detected by family-specific PCRs targeting the same family. The discrepancy of detected viruses by different detection approaches suggests that a combined approach using different detection methods is necessary for virus discovery studies.

Bats have been recognized as potential reservoir host of several highly pathogenic viruses like Hendra virus, Nipah virus, Marburg virus and SARS-CoV viruses ${ }^{1-5}$. With more than 60 million years of evolution they belong to the oldest mammals we know today ${ }^{6}$. Furthermore, bats are often discussed as being special in the way they react to infections. Bat immunology is aiming to shed light on the very special way bats and pathogens coevolve $\mathrm{e}^{7-9}$. Numerous publications and studies are focusing on virus discovery in this very distinct mammalian order and accelerate the publication of thousands of novel viral sequences. While mainly family-specific PCR approaches were used to detect novel virus strains during the first years of virus discovery in bats, next generation sequencing approaches have gained in significance in recent years. The metagenomic view on viruses (virome) supports the simultaneous detection of viruses in individual or pooled samples within a very short time. However, for samples with a high host nucleotide background it became apparent that some sort of purification procedure might be necessary for NGS approaches to increase significantly the number of obtained viral sequences from biological samples. Various protocols have been published to address this problem ${ }^{10-12}$.

By now, already 16 bat virome studies are available at PubMed and numerous additional ones are presently being conducted. In most studies guano, feces or oral swabs were used as sample sources ${ }^{13-25}$ (Table 1). Bat organ tissues were used for only three studies which were performed in Southeast China, Myanmar ${ }^{26,27}$ and France ${ }^{28}$. In the first two studies, either bought or trapped live bats of different Asian species were used after immediate dissecting ${ }^{26}$. The latter study was carried out in France where only nine bat carcasses belonging to five species were used ${ }^{28}$. Presently, the database of bat-associated viruses lists more than 800 viruses in European bats, mostly detected by family-specific PCRs ${ }^{29}$.

This paper summarizes comprehensive results obtained during a study on German bats by three different detection approaches, namely PCR, cell culture virus isolation and NGS. The results of virome sequencing of 16 different bat species are highlighted. Furthermore, we discuss the suggestion of the virome sequencing approach replacing conventional virus discovery methods such as family-specific PCR and cell culture virus isolation.

\footnotetext{
${ }^{1}$ Centre for Biological Threats and Special Pathogens, Robert Koch Institute, Seestrasse 10, 13353 Berlin, Germany. ${ }^{2}$ Robert Koch Institute, Methodology and Research Infrastructure 2, Genome Sequencing, Berlin, Germany. ${ }^{3}$ Robert Koch Institute, Methodology and Research Infrastructure 1, Bioinformatics, Berlin, Germany. ${ }^{4}$ Leibniz Institute for Zoo and Wildlife Research, Berlin, Germany. ${ }^{\circledR}$ email: kohlc@rki.de
} 


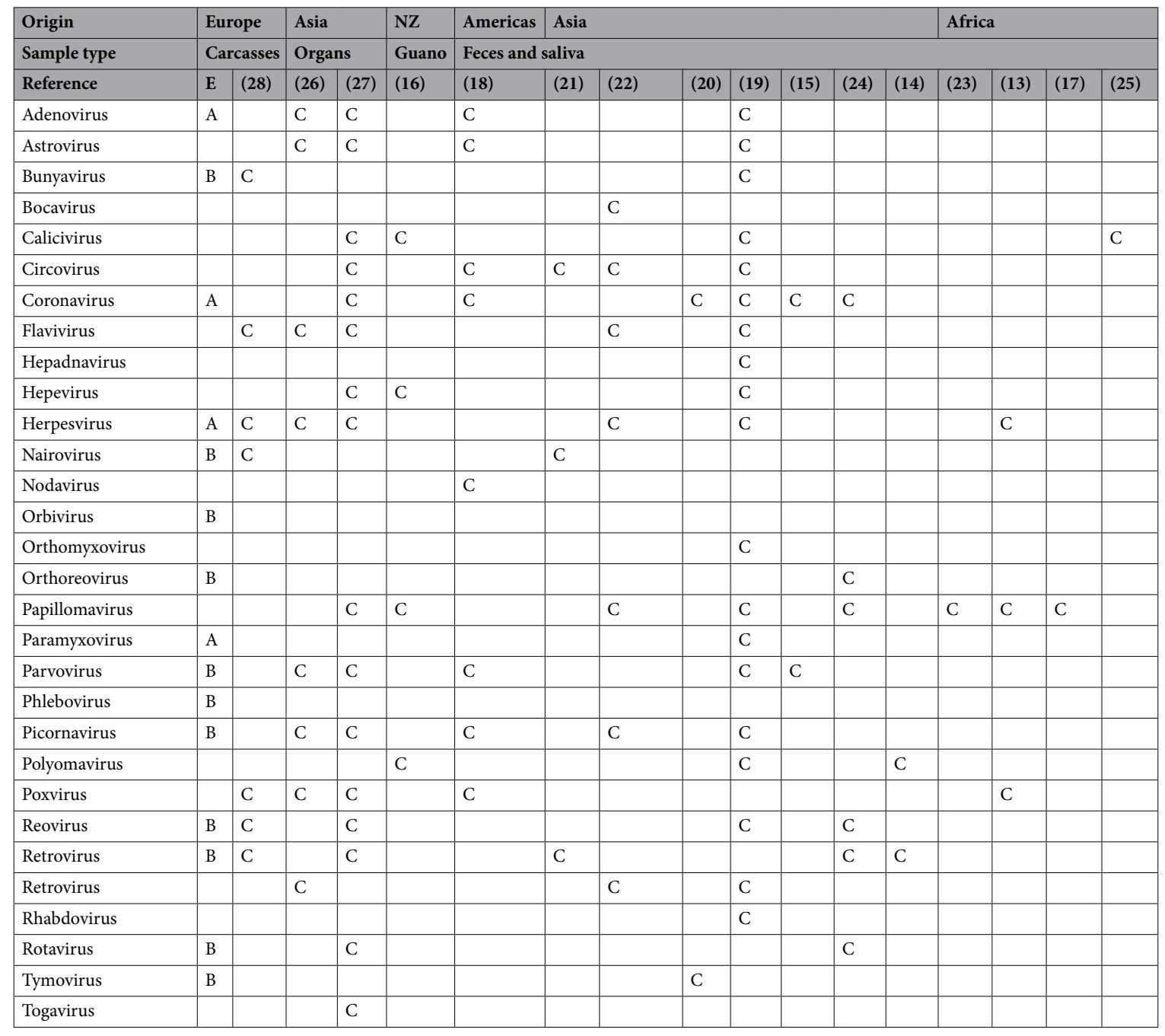

Table 1. Comparison of results from virus discovery studies conducted. The viral sequences obtained by family-specific PCR are marked with "A" and viral sequences obtained by virome sequencing are marked with " $\mathrm{B}$ ". Adenovirus and reoviruses were also isolated. The " $\mathrm{C}$ " indicates the finding of the respective viruses found by other studies. $E$ the results from this study, NZ New Zealand.

\section{Results}

Screening with family-specific PCRs. The PCR screening resulted in the detection of several novel viral sequences for paramyxoviruses, adenoviruses, herpesviruses and coronavirus (Table 2). Sequences found for paramyxoviruses, adenoviruses (polymerase) and herpesviruses have been published before ${ }^{30-34}$. A novel coronavirus $(\mathrm{CoV})$ sequence is described here for the first time. No arenaviruses, filoviruses, nairo- and phenuiviruses, hantaviruses and flaviviruses were detected by PCR.

Coronavirus. A novel coronavirus sequence was obtained using the family-specific CoV PCR published earlier by de Souza Luna et al. ${ }^{35}$. Bat number E210/09 (Pipistrellus pipistrellus) was found to be positive for CoV in the intestinal sample. Phylogenetic analysis revealed that the sequence was most closely related to alphacoronaviruses of group 1 (Supplementary Fig. S1). The sequence (296 nt) was named Bat CoV 210/09 P.pip and is available under accession number MN851285.

Virus isolation in cell culture. Virus isolation was attempted from all 375 samples in either two out of six different cell culture systems. Two novel isolates were obtained, Bat orthoreovirus T3/Bat/Germany/342/08 and Bat adenovirus $2^{30,31,36}$. Both viruses had initially been cultivated in Vero cell lines (Supplementary Table S1).

Virome sequencing and phylogenetic reconstruction. Sequencing of the nine bat pools via Illumina HiSeq revealed 127,338,644 reads after trimming. In Fig. 1 the raw output obtained from MEGAN6 ${ }^{37}$ is depicted. Though MEGAN6 displayed a large number of hits for different viral families, several hits did not meet the qual- 


\begin{tabular}{|c|c|c|c|c|}
\hline PCR assays & Assay type & $\begin{array}{l}\text { Bats } \\
\# / \text { novel/size }\end{array}$ & Assay reference & Virus reference \\
\hline \multicolumn{5}{|l|}{ Adenoviridae } \\
\hline Adenoviridae (Polymerase) & Pan & $79 / 14 / 203^{\mathrm{H}}$ & $(67)$ & $(31)$ \\
\hline \multicolumn{5}{|l|}{ Arenaviridae } \\
\hline Old-World & Pan & $0 / 0 / 60$ & $(61)$ & Unpublished \\
\hline \multicolumn{5}{|l|}{ Bunyaviridae } \\
\hline Hanta Virus Puumala & cPCR & $0 / 0 / 150$ & In-house design RKI & $(71)$ \\
\hline Hanta Virus Dobrava & cPCR & $0 / 0 / 150$ & In-house design RKI & $(71)$ \\
\hline Hanta Virus Tula & cPCR & $0 / 0 / 150$ & In-house design RKI & $(71)$ \\
\hline Hantaviruses & Pan & $0 / 0 / 180$ & $(64)$ & Unpublished \\
\hline Nairoviruses & Pan & $0 / 0 / 150$ & $(65)$ & Unpublished \\
\hline Phleboviruses & Pan & $0 / 0 / 150$ & (65) & Unpublished \\
\hline \multicolumn{5}{|l|}{ Coronaviridae } \\
\hline Coronaviridae & Pan & $1 / 1 / 240$ & $(35)$ & Unpublished (MN851285) \\
\hline Coronaviridae & Pan & $0 / 0 / 90$ & In-house design RKI & unpublished \\
\hline \multicolumn{5}{|l|}{ Flaviviridae } \\
\hline Flaviviridae & Pan & $0 / 0 / 150$ & In-house design & Unpublished \\
\hline Flaviviridae & Pan & $0 / 0 / 180$ & $(63)$ & $(71)$ \\
\hline \multicolumn{5}{|l|}{ Herpesviridae } \\
\hline BatGHV1 & cPCR & $1 / 1 / 180$ & $(34)$ & $(71)$ \\
\hline BatGHV3 & cPCR & $7 / 1 / 180$ & $(34)$ & $(71)$ \\
\hline BatGHV4 & cPCR & $22 / 1 / 210$ & $(34)$ & $(71)$ \\
\hline BatGHV5 & cPCR & $11 / 1 / 210$ & $(34)$ & $(71)$ \\
\hline BatGHV6 & cPCR & $24 / 1 / 210$ & $(34)$ & $(71)$ \\
\hline BatGHV7 & cPCR & $2 / 1 / 210$ & $(34)$ & $(71)$ \\
\hline BatBHV1 & cPCR & $1 / 1 / 180$ & $(34)$ & $(71)$ \\
\hline Herpesviridae & pan & $11 / 9 / 60$ & $(68)$ & Unpublished \\
\hline \multicolumn{5}{|l|}{ Orthomyxoviridae } \\
\hline Influenza A & qPCR & $0 / 0 / 330$ & (66) & - \\
\hline \multicolumn{5}{|l|}{ Paramyxoviridae } \\
\hline Res-Mor-Hen & Pan & $2 / 2 / 120$ & $(60)$ & $(32)$ \\
\hline PAR & Pan & $3 / 3 / 180$ & $(60)$ & $(32)$ \\
\hline \multicolumn{5}{|l|}{ Poxviridae } \\
\hline Low GC poxviruses & Pan & $0 / 0 / 263$ & $(70)$ & Unpublished \\
\hline
\end{tabular}

Table 2. Results PCR screening. Bats were screened for the presence of virus nucleic acids by different PCR assays. pan generic family-specific assay, $q P C R$ quantitative real-time PCR, $c P C R$ conventional specific PCR. *\#/novel/size: \#, number of positive samples; novel, number of novel viruses obtained; size, bat sample size.

${ }^{\mathrm{H} S}$ creened in collaboration with our Hungarian colleagues (see Ref. ${ }^{33}$ ).

ity criteria. These reads could not be remapped to reference sequences, revealed non-plausible BLASTx/BLASTn results (i.e. genomic DNA of bats) or shared 100 percent identity to sequences obtained before (possible crosscontamination). Supplementary Table S2 summarizes the number of filtered reads (length/quality) obtained per pool with the number of viral reads (w/o phages) finally checked for quality and allocated by Diamond ${ }^{38}$, MEGAN6 and further analysis. In Fig. 2 the overall number of viral reads in all pools per virus family is summarized.

Viruses of nine different families and orders (Parvoviridae, Picornaviridae, Totiviridae, Mononegavirales, Reoviridae, Bunyavirales, Tymovirus, Retroviridae and phages) were confirmed within the bat samples by virome sequencing and further analysis. For each family, selected viruses were retested by specific PCRs in the individual bats' organs. For the viruses of highest interest, phylogenetic reconstructions were calculated as described in the methods section.

All viruses were confirmed by sequence assembly and comparison to reference strains and to each other as described in the methods section. Most of the viruses were tested back with designed specific primers, PCR and Sanger sequencing. The individual length of obtained contigs, the accession number of the reference sequence and the pairwise identity on nt and aa level are summarized in Table 3. The accession numbers of all obtained viral sequences are available in Table 4 . The full description of the results is given in the supplemental section.

Parvoviridae. Parvoviruses $(\mathrm{n}=5)$ were found in pools $1,2,3$ and 9 belonging to the subspecies Densovirinae (146,313 reads) and Parvovirinae (20,296 reads). The virus sequences were named after the order of appearance and in relation to reference strains: Blatella Germanica densovirus-like virus 1, Blatella Germanica densovirus- 


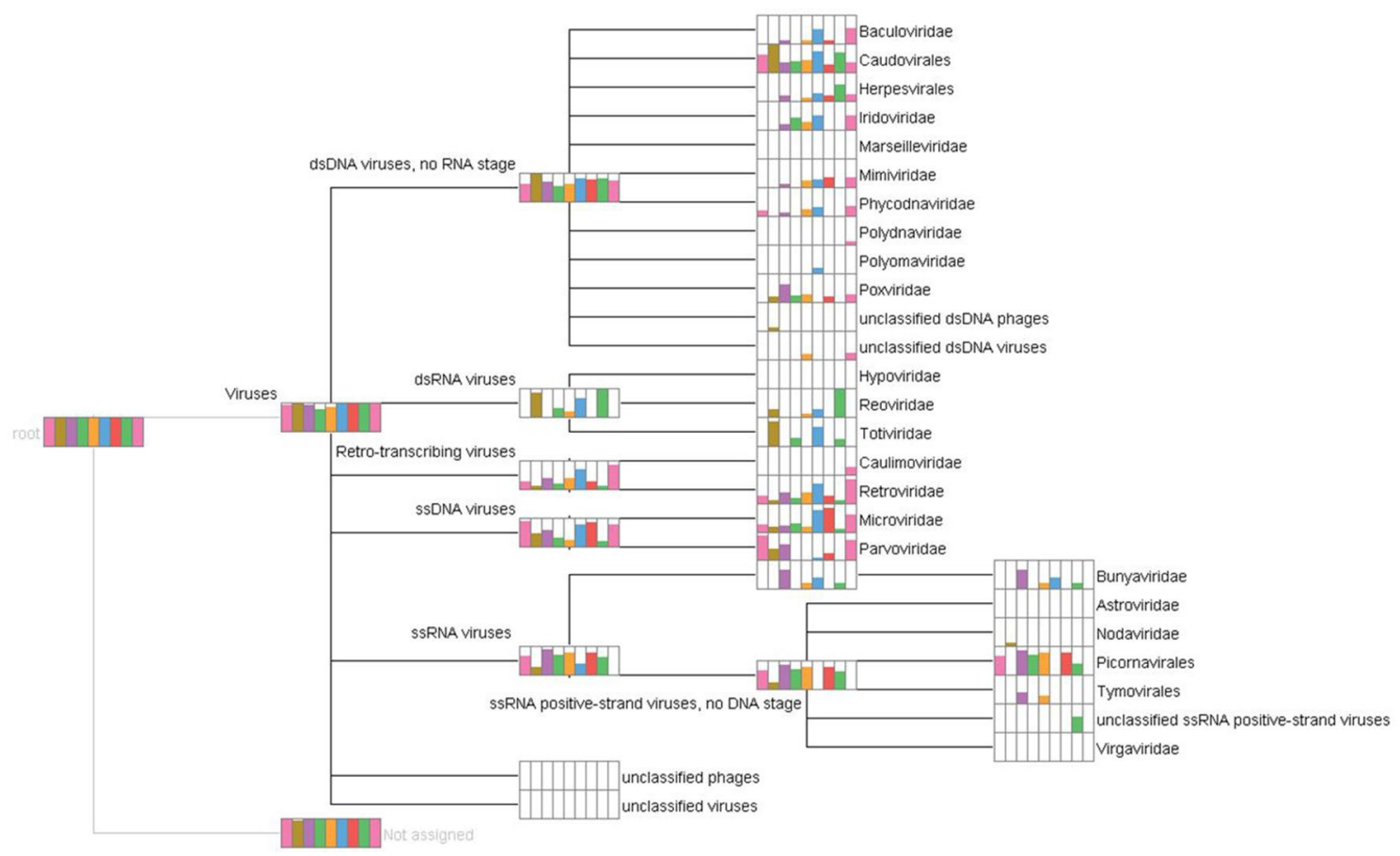

Figure 1. Comparison of all pools with MEGAN6. The different colors stand for the individual pools: pool 1 pink, pool 2 light brown, pool 3 brown, pool 4 light green, pool 5 yellow, pool 6 blue, pool 7 red, pool 8 green, pool 9 light pink. The height of the color bars indicates the percentage of viruses found in the corresponding nodes of the taxonomic tree.

like virus 2, Blatella Germanica densovirus-like virus 3, Parus major densovirus-like virus and Bat bufavirus (accession numbers: MN851295, MN851277, MN851278, MN851279 and MN851293).

Picornaviridae. Picornaviruses $(\mathrm{n}=7)$ were found in pools $1,2,3,4,5,7$ and $8(1,039,379$ reads), all of which were related to King virus UWV1, King virus UWV2, Tetnovirus 1 or Hubei Picorna-like virus. The virus sequences were named after the order of appearance and in relation to reference strains: King virus UWV1like virus, King virus UWV2-like virus 1, King virus UWV2-like virus 2, King virus UWV2-like virus 3, King virus UWV2-like virus 4, Tetnovirus 1-like virus and Hubei Picorna-like virus. Obtained sequences are available under the following accession numbers: MN851294, MN851280, MN851281, MN851282, MN851283, MN851284 and MN851286.

Totiviridae. One totivirus was found in pool 2 (881,349 reads) which appears to be most closely related to Eimeria tenella RNA virus 1. The virus sequence was named in relation to the reference strain: Picorna Eimeria tenella virus 1-like virus. The obtained sequence is available under the following accession number: MN851287.

Mononegavirus. A distinct sequence, related to mononegaviruses Wenzhou tapeworm virus and Midway virus, was identified in pool 2 (14,628 reads). The obtained sequence is available under the following accession number: MN851288. Phylogenetic reconstruction of $665 \mathrm{nt}$ (polymerase) Wenzhou tapeworm virus-like virus in comparison to the reference strains of Mononegavirales is displayed in (Supplementary Fig. S2).

Reoviridae. Reoviruses $(n=3)$ were found in pools 2,5 and $8(97,161$ reads) and include related reoviruses of three distinct genera orbivirus (related to Bat orbivirus China-unpublished AccNo. MH144554.1), rotavirus (related to Human rotavirus A-like virus) and orthoreovirus (Bat orthoreovirus T3/Bat/Germany/342/08). Bat orthoreovirus T3/Bat/Germany/342/08 had been isolated before from the same sample set; no further analysis was conducted here ${ }^{30}$. Obtained sequences are available under the following accession numbers: MN851289, MN851290 and MN851291. Phylogenetic reconstruction of orbiviruses (780 nt) and rotaviruses (450 nt, VP4) in comparison to the two novel sequences is displayed in Figs. 3 and 4, respectively.

Nairoviridae. Nairoviruses $(n=3)$ were found in pools 3, 5 and 6 (8132 reads). The found virus sequences share the highest identity with Issyk-Kul virus, Sapphire II virus and Avalon Bres virus. Obtained sequences are available under the following accession numbers: MN851301, MN851292 and MN851296. Phylogenetic reconstruction of Sapphire II-like virus and Issyk-Kul-like virus with other members of nairoviruses (457 nt, L-segment) is displayed in Figs. 5 and 6. Because of missing sequence homology between Avalon Bres virus-like virus with the other two strains, the phylogenetic reconstruction is not shown, but available on request. 


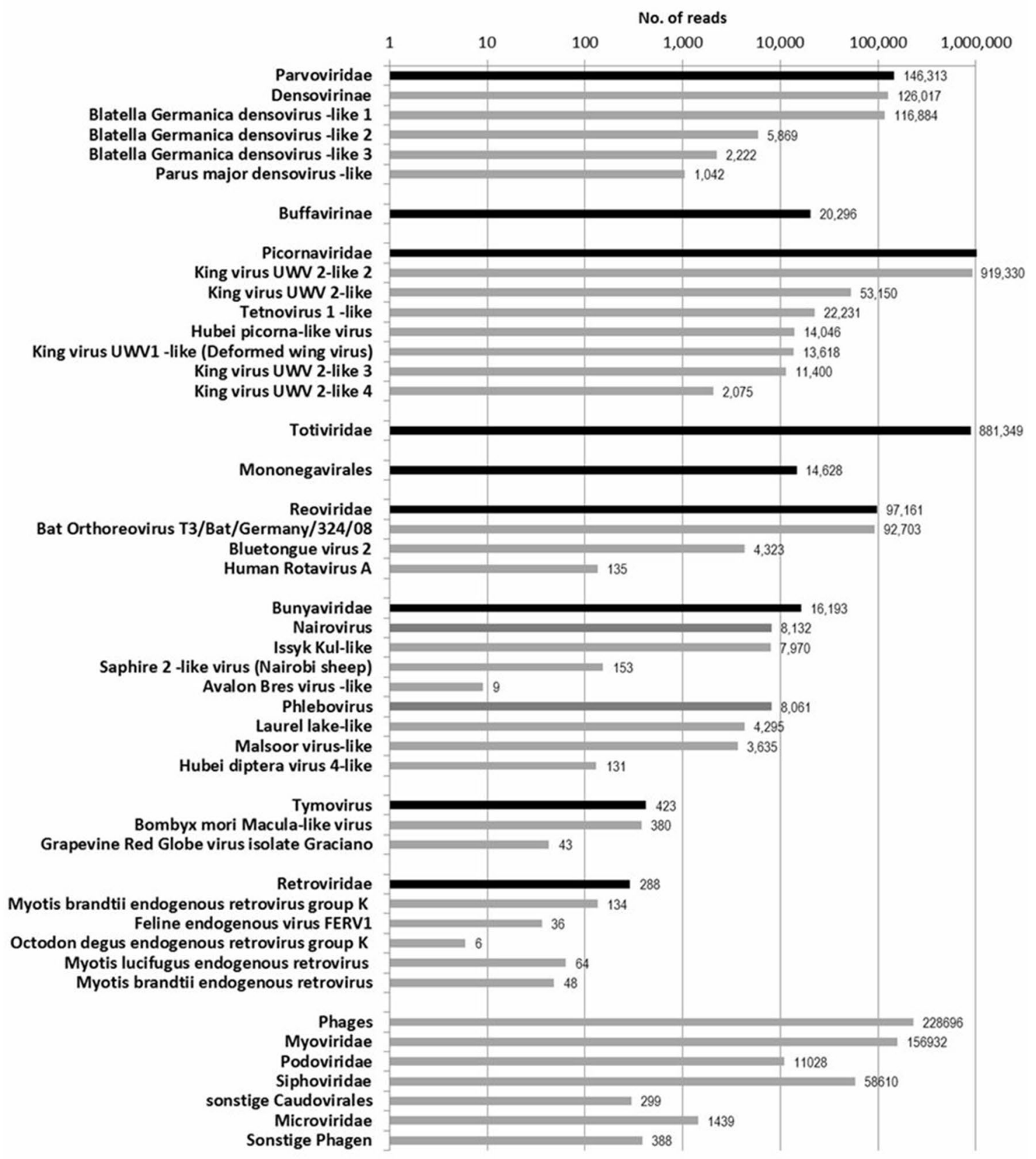

Figure 2. Schematic summary of the number of reads related to viruses classified by viral genus, subfamily and family. Viruses that did not meet the quality criteria were excluded.

Phenuiviridae. Phenuiviruses $(\mathrm{n}=3)$ were found in pools 3 and 8 (8061 reads). The found virus sequences share the highest identity with the strains Laurel Lake virus (genus Laulavirus) $(n=2)$ and Malsoor virus/SFTS $(n=1)$ (genus Banyangvirus). Obtained sequences $>200 \mathrm{nt}$ are available under the following accession numbers: MN851297 and MN857542. Phylogenetic reconstruction of Malsoor-like virus with other members of phenuiviruses ( $2578 \mathrm{nt}$, glycoprotein) is displayed in Fig. 7. Laurel Lake-like viruses 1 and 2 with other members of phenuiviruses is displayed in the supplemental section (Supplementary Fig. S3).

Tymovirus. Tymoviruses $(\mathrm{n}=2)$ were found in pools 3 and 5 (423 reads). The found virus sequences share the highest identity with the strains Bombyx mori latent virus and Grapevine Red Globe virus. The virus sequences were named after the order of appearance and in relation to reference strains: Bombyx mori latent-like virus and Grapevine Red Globe-like virus. Obtained sequences are available under the following accession numbers: MN851298 and MN851299. 


\begin{tabular}{|c|c|c|c|c|c|c|}
\hline & Virus/Acc No of best match & $\#$ & Species & Reads & Longest contig & ID nt/aa \% \\
\hline \multirow{12}{*}{ Parvoviridae } & Blatella Germanica densovirus-like 1 & 1 & Myotis myotis & 116,884 & $3727 \mathrm{nt}$ & $97.0 / 98.0$ \\
\hline & JQ320376.1 & & Pipistrellus kuhlii & & $98.5 \%$ genome & \\
\hline & & & Myotis nattereri & & & \\
\hline & Blatella Germanica densovirus-like 2 & 3 & Eptesicus nilssonii & 5869 & $614 \mathrm{nt}$ & 98.0/99.0 \\
\hline & KU727766.1 & & & & & \\
\hline & Blatella Germanica densovirus-like 3 & 9 & Myotis daubentonii & 2222 & $983 \mathrm{nt}$ & $99.0 / 99.0$ \\
\hline & JQ320376.1 & & Vespertilio murinus & & & \\
\hline & Parus major densovirus-like & 3 & Eptesicus nilssonii & 1042 & $1,568 \mathrm{nt}$ & $98.0 / 95.0$ \\
\hline & KU727766 & & & & $67.6 \%$ genome & \\
\hline & Bat Bufavirus & 2 & Nyctalus noctula & 20,296 & $722 \mathrm{nt}$ & $88.0 / 92.0$ \\
\hline & Bat parvovirus isolate BtNv-PV & & & & $40.5 \%$ genome & \\
\hline & KJ641683 & & & & & \\
\hline \multirow{14}{*}{ Picornaviridae } & King virus UWV1-like & 1 & Myotis myotis & 13,618 & $2355 \mathrm{nt}$ & $99.0 / 99.0$ \\
\hline & KX779453 & & Pipistrellus kuhlii & & $40.3 \%$ genome & \\
\hline & & & Myotis nattereri & & & \\
\hline & King virus UWV 2-like & 3 & Eptesicus nilssonii & 53,150 & $6010 \mathrm{nt}$ & $97.0 / 99.0$ \\
\hline & KX779454.1 & & & 1022 & $100 \%$ genome & \\
\hline & King virus UWV 2-like 2 & 5 & Pipistrellus pipistrellus & 919,330 & $2,438 \mathrm{nt}$ & $98.0 / 99.0$ \\
\hline & KX779453.1 & & & & & \\
\hline & King virus UWV 2-like 3 & 8 & Plecotus auritus & 11,400 & $971 \mathrm{nt}$ & $97.0 / 98.0$ \\
\hline & KX779453.1 & & Pipistrellus nathusii & & & \\
\hline & Tetnovirus 1-like & 2 & Nyctalus noctula & 22,231 & $710 \mathrm{nt}$ & $70.0 / 78.0$ \\
\hline & HM480375 & 4 & Myotis mystacinus & 2507 & $46.7 \%$ genome & \\
\hline & Hubei picorna-like virus & 8 & Plecotus auritus & 14,046 & $481 \mathrm{nt}$ & $66.0 / 59.0$ \\
\hline & KX883698.1 & & Pipistrellus nathusii & & $4.01 \%$ genome & \\
\hline & King virus UWV 2-like 4 & 7 & Eptesicus serotinus & 2075 & $1523 \mathrm{nt}$ & $98.80 \%$ \\
\hline \multirow{2}{*}{ Totiviridae } & Eimeria Tenella RNA virus 1-like & 2 & Nyctalus noctula & 881,349 & $2059 \mathrm{nt}$ & -150.0 \\
\hline & KJ363185 & & & & $81.3 \%$ genome & \\
\hline \multirow{2}{*}{ Mononegavirus } & Wenzhou tapeworm virus 1-like & 2 & Nyctalus noctula & 14,628 & $627 \mathrm{nt}$ & $-/ 35.0$ \\
\hline & KX884436 & & & & $4 \%$ genome & \\
\hline \multirow{6}{*}{ Reovirus } & Irlbach Bat Orbivirus & 2 & Nyctalus noctula & 4323 & $783 \mathrm{nt}$ & $70.69 / 81.0$ \\
\hline & MH144554.1 (Bat Orbivirus China) & & & & $4 \%$ genome & \\
\hline & Hannover bat rotavirus & 5 & Pipistrellus pipistrellus & 135 & $424 \mathrm{nt}$ & $58.0 / 57.0$ \\
\hline & GQ398017 (Human Rotavirus A) & & & & & \\
\hline & $\begin{array}{l}\text { Bat Orthoreovirus T3/Bat/Ger- } \\
\text { many/324/08 }\end{array}$ & 8 & Pipistrellus nathusii & 92,703 & $1296 \mathrm{nt}$ & $100 / 100$ \\
\hline & Q412758 & & Plecotus auritus & & $90 \%$ genome & \\
\hline \multirow{12}{*}{ Bunyavirus } & Issyk-Kul virus strain PbGER & 3 & Eptesicus nilssonii & 5,580 & $1281 \mathrm{nt}$ & $95.0 / 99.0$ \\
\hline & KR709221.1 Issyk-Kul virus & & & & 93.5\% segment & \\
\hline & Zwiesel bat banyangvirus & 3 & Eptesicus nilssonii & 3,635 & $2,578 \mathrm{nt}$ & $70.0 / 72.0$ \\
\hline & KF186495.1 Malsoor virus, SFTS & & & & $90.0 \%$ genome & \\
\hline & Berlin bat nairovirus & 5 & Pipistrellus pipistrellus & 153 & $384 \mathrm{nt}$ & $69 / 58$ \\
\hline & KU925485 Sapphire II-like virus & & & & & \\
\hline & Bavarian bat lalavirus & 8 & Pipistrellus nathusii & 131 & $176 \mathrm{nt}$ & $-/ 50.0$ \\
\hline & NC-043671 Laurel Lake virus-like 1 & & Plecotus auritus & & & \\
\hline & Wittenau bat nairovirus & 6 & Pipistrellus pipistrellus & 9 & $377 \mathrm{nt}$ & $72 / 50$ \\
\hline & KU925443 Avalon Bres virus & & Pipistrellus pygmaeus & & & \\
\hline & Munich bat lalavirus & 8 & Pipistrellus nathusii & 4295 & $528 \mathrm{nt}$ & $-/ 43.0$ \\
\hline & NC_043679.1 Laurel Lake-like virus 2 & & Plecotus auritus & & & \\
\hline \multirow{4}{*}{ Tymovirus } & Bombyx mori latent virus & 3 & Eptesicus nilssonii & 380 & $1179 \mathrm{nt}$ & $-/ 50.0$ \\
\hline & NC038331 & & & & & \\
\hline & Grapevine Red Globe virus isolate & 5 & Pipistrellus pipistrellus & 43 & $320 \mathrm{nt}$ & $76.0 / 78.0$ \\
\hline & KX109927.1 & & & & & \\
\hline
\end{tabular}




\begin{tabular}{|c|c|c|c|c|c|c|}
\hline & Virus/Acc No of best match & \# & Species & Reads & Longest contig & ID nt/aa \% \\
\hline \multirow{5}{*}{ Retroviridae } & Myotis myotis endogenous retrovirus & 1 & Myotis myotis & 134 & $664 \mathrm{nt}$ & \\
\hline & XM_014547948 Myotis brandtii ERV & & Pipistrellus kuhlii & & & \begin{tabular}{|l|}
$97.0 / 93.0$ \\
\end{tabular} \\
\hline & & & Myotis nattereri & & & \\
\hline & $\begin{array}{l}\text { Pipistrellus pipistrellus endogenous } \\
\text { Retrovirus } \\
\text { XP_014403434 } \\
\text { FERV1-like } \\
\end{array}$ & 6 & Pipistrellus pipistrellus & 36 & $558 \mathrm{nt}$ & 97.0/93.0 \\
\hline & $\begin{array}{l}\text { Myotis daubentonii endogenous retro- } \\
\text { virus } \\
\text { XR_001346663.2 } \\
\text { Myotis lucifugus endogenous retrovirus- } \\
\text { like }\end{array}$ & 9 & $\begin{array}{l}\text { Myotis daubentonii } \\
\text { Vespertilio murinus }\end{array}$ & 64 & $279 \mathrm{nt}$ & $95.0 / 90.2$ \\
\hline
\end{tabular}

Table 3. Virus results per virus family. Acc No, Accession number; \#, Pool number; ID nt/aa, Identity nucleic acid/amino acid; nt, nucleotides. -, no homology was found.

\begin{tabular}{|c|c|c|}
\hline Acc. No. & Final name of novel virus & Related virus \\
\hline MN851277 & Blatella Germanica densovirus-like virus 2 & Blatella Germanica densovirus \\
\hline MN851278 & Blatella Germanica densovirus-like virus 3 & Blatella Germanica densovirus \\
\hline MN851279 & Parus major densovirus-like virus & Parus major densovirus \\
\hline MN851280 & King virus UWV 2-like virus & King virus UWV 2 \\
\hline MN851281 & King virus UWV 2-like 2 virus & King virus UWV 2 \\
\hline MN851282 & King virus UWV 2-like 3 virus & King virus UWV 2 \\
\hline MN851283 & King virus UWV 2-like 4 virus & King virus UWV 2 \\
\hline MN851284 & Tetno virus 1-like virus & Tetno virus 1 \\
\hline MN851285 & Bat coronavirus 210/09 P.pip & Bat alphacoronaviruses \\
\hline MN851286 & Hubei picorna-like virus & Hubei picorna virus \\
\hline MN851287 & Eimeria Tenella RNA virus 1-like virus & Eimeria Tenella RNA virus 1 \\
\hline MN851288 & Berlin bat mononegavirus (BbmV) & Wenzhou tapeworm 1 virus \\
\hline MN851289 & Irlbach bat orbivirus (IboV) & Sathuvachari virus \\
\hline MN851290 & Hannover bat rotavirus (HbrV) & Rotaviruses type A \\
\hline MN851291 & Bat orthoreovirus T3/Bat/Germany/342/08 & Bat orthoreovirus T3/Bat/Germany/342/09 \\
\hline MN851292 & Berlin bat nairovirus $(\mathrm{BbnV})$ & Sapphire II virus \\
\hline MN851293 & Bat bufavirus & Bat parvovirus BtNv-PV/SC2013 \\
\hline MN851294 & King virus UWV 1-like virus & King virus UWV 1 \\
\hline MN851295 & Blatella Germanica densovirus-like virus 1 & Blatella Germanica densovirus \\
\hline MN851296 & Wittenau bat nairovirus $(\mathrm{WbnV})$ & Avalon Bres virus \\
\hline MN851297 & Munich bat lalavirus (MblV) & Laurel Lake virus \\
\hline MN851298 & Bombyx mori latent-like virus & Bombyx mori latent virus \\
\hline MN851299 & Grapevine red globe-like virus & Grapevine red globe virus \\
\hline MN851300 & Pipistrellus pipistrellus endogenous retrovirus & FERV1 \\
\hline MN851301 & Issyk-Kul virus strain PbGER & Issyk-Kul virus \\
\hline MN851301 & Myotis myotis endogenous retrovirus & Myotis brandtii endogenous retrovirus \\
\hline MN851302 & Myotis daubentonii endogenous retrovirus & Myotis lucifugus endogenous retrovirus \\
\hline MN851303 & Zwiesel bat banyangvirus & Malsoor virus/SFTS \\
\hline
\end{tabular}

Table 4. Names and accession numbers of novel virus sequences.

Retroviridae. Retroviruses $(\mathrm{n}=5)$ were found in pools 1, 6 and 9 (234 reads). The found viral sequences share the highest identity with the strains Myotis brandtii endogenous retrovirus, Feline endogenous virus FERV1, and Myotis lucifugus endogenous retrovirus. The virus sequences were named after their host and in relation to reference strains: Pipistrellus pipistrellus endogenous retrovirus, Myotis myotis endogenous retrovirus, Myotis daubentonii endogenous retrovirus. Obtained sequences are available under the following accession numbers: MN851300, MN851302 and MN851303. Phylogenetic reconstructions for Myotis brandtii endogenous retrovirus-like sequence and Myotis lucifugus endogenous retrovirus-like sequence are available on request.

Phages. Numerous phages were found in all pools (226,696 reads). Most of the phages belong to the Myoviridae and Podoviridae, followed by the Siphoviridae. 


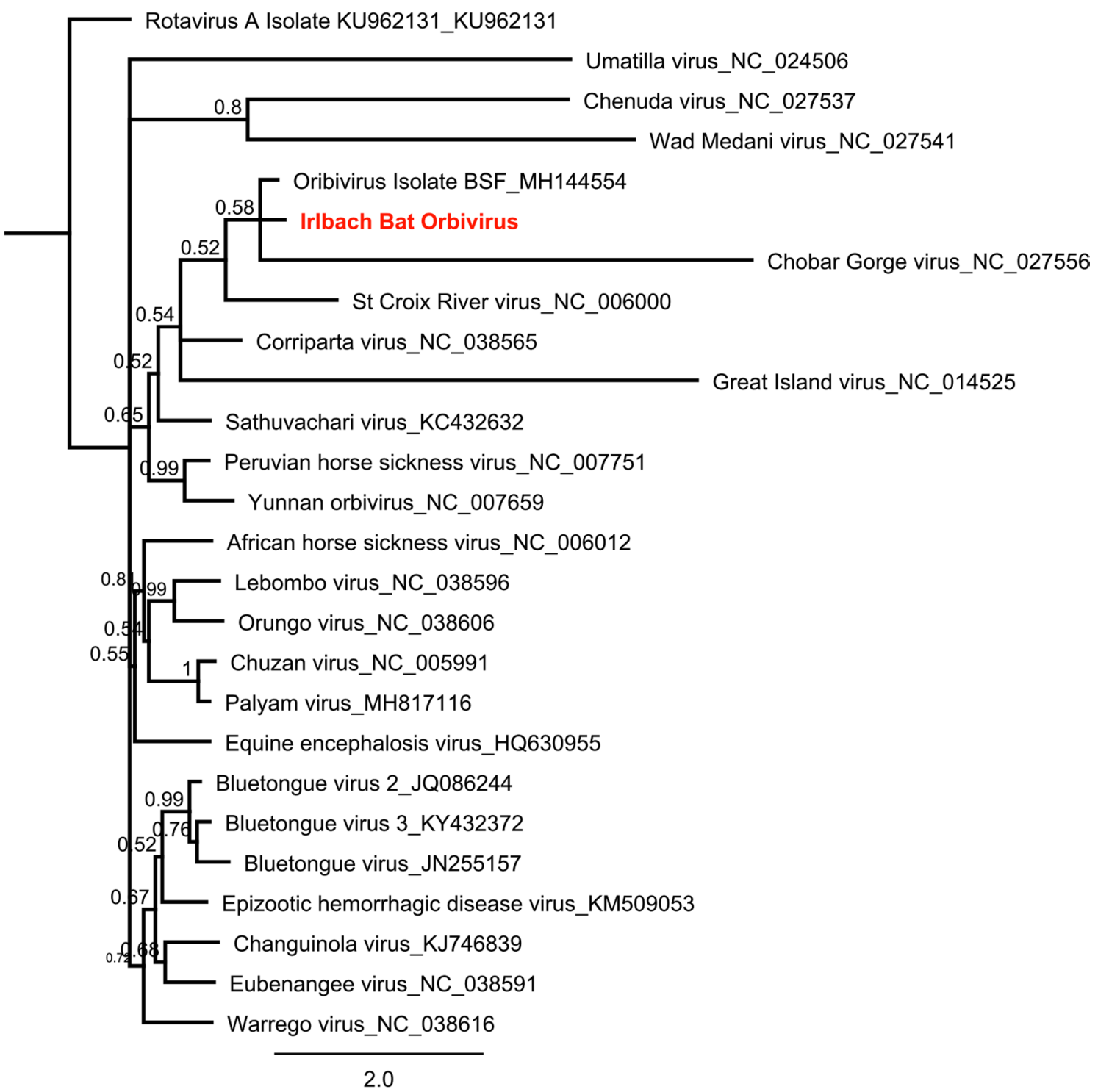

Figure 3. Phylogenetic reconstruction of Orbiviruses ML, 1 million, $780 \mathrm{nt}$ of the VP4 protein. Reconstruction was performed via the Bayesian MCMC approach using MrBayes with the following settings (burn-in, 10\%; frequency, 200; chain length, 1 million to 10 million, depending on when a standard derivation of below 0.025 was reached $)^{78}$. Reconstructed trees were visualized using FigTree and posterior probabilities were depicted for each node (http://tree.bio.ed.ac.uk/software/figtree/).

Comparison of PCR and virome results. Of all viruses identified by family-specific PCR in the original samples, none was found by metagenomic sequencing. Vice versa, none of the viruses found by the metagenomic virome approach was detected by family-specific PCRs targeting the same family. The initially isolated reovirus T3/Bat/Germany/342/08 was identified by virome sequencing within the original sample.

\section{Discussion}

Virome sequencing of German bat carcasses of 16 bat species resulted in a high variety of confirmed viral sequences of parvoviruses, picornaviruses, totiviruses, reoviruses, nairoviruses, phenuiviruses, tymoviruses, retroviruses and several phages. In addition to the confirmed viral sequences, several sequencing reads were identified that shared a high homology and identity to other viruses. These high-identity reads were excluded as they were very likely false-positive results (i.e. poxviruses) (Fig. 1). The occurrence of false-positive results in virome sequencing is well known and has been described before ${ }^{39}$. Table 1 compares the results obtained from different bat virome studies with our findings. Virome profiles found in our study are generally comparable to those in other studies. Several Picornaviruses, Parvoviruses, Retroviruses, Tymoviruses and Totiviruses were identified in the nine distinct virome profiles of European bats (Supplementary Tables S3, S4, S5, S6, S7, S8, S9, S10 and $\mathrm{S} 11)$. However, some of the viruses detected in our study are particularly interesting as they are phylogenetically closely related to viruses that can cause diseases in humans, or they are the first description of these viruses in 


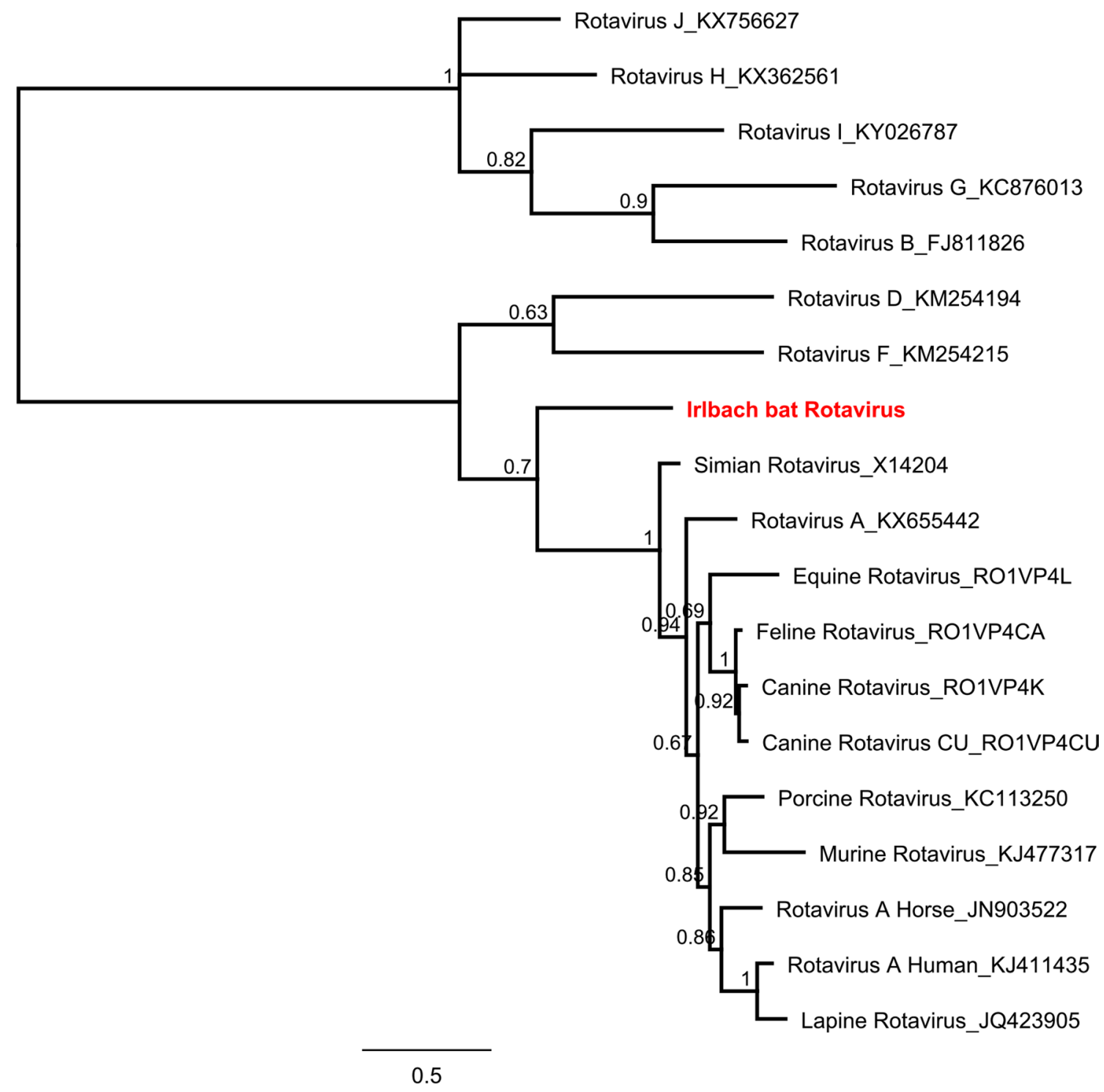

Figure 4. Phylogenetic reconstructions of Rotaviruses ML, 1 million, 450 nt of the VP4 protein. Reconstruction was performed via the Bayesian MCMC approach using MrBayes with the following settings (burn-in, 10\%; frequency, 200; chain length, 1 million to 10 million, depending on when a standard derivation of below 0.025 was reached $)^{78}$. Reconstructed trees were visualized using FigTree and posterior probabilities were depicted for each node (http://tree.bio.ed.ac.uk/software/figtree/).

certain bat species or within the European geographical range. The following discussion gives a summary of the viruses of highest interest. The full discussion on these viruses can be found in the supplemental section.

Six Bunyaviruses were identified in this study (nairoviruses and phenuiviruses). Nairoviridae are a family within the order Bunyavirales and named after the type species Nairobi sheep disease virus ${ }^{40}$. The majority of nairoviruses is transmitted by ticks and several are capable of causing severe diseases in humans and animals ${ }^{40}$. Bat nairoviruses have been reported before: Ahun nairovirus (KF170224) and Gossas virus (KR534878) ${ }^{21,28,41}$. Other nairoviruses of bats have been described and form two monophyletic genogroups within the nairoviruses, Keterah and Kasokero ${ }^{41}$.

In this study three novel nairoviral sequences were detected and confirmed in tissues from German bats; these are related to Issyk-Kul virus (Id 95\% nt; 99\% aa), Sapphire II virus (Id 85\% nt; 54\% aa) and Avalon Bres virus (Id $71 \% \mathrm{nt} ; 50 \%$ aa). Nine out of twelve Eptesicus nilssonii bats in pool 3 were infected with a yet undescribed IssykKul virus strain (Supplementary Table S5). The phylogenetic reconstruction clearly allocated this novel strain to already described Issyk-Kul viruses within the Keterah genogroup (Fig. 6) ${ }^{41}$. Issyk-Kul virus had first been isolated in 1970 from a Nyctalus noctula bat in Kyrgyzstan and later on in Tajikistan and Kazakhstan ${ }^{42,43}$. IssykKul virus was described to cause sporadic febrile outbreaks in humans with headache, myalgia and nausea ${ }^{42,44}$. It is assumed that Issyk-Kul virus can be transmitted by tick bites and exposure to bat feces and urine, eventually ${ }^{42}$. The Issyk-Kul-like virus described here was found predominantly in liver, spleen and lung tissues of the respective bats, indicating systemic infection of bats instead of solely passaging intestinal tick content. We named the novel Issyk-Kul virus strain "PbGER" after its origin in Prackenbach, Germany (Table 4). The novel Issyk-Kul virus 


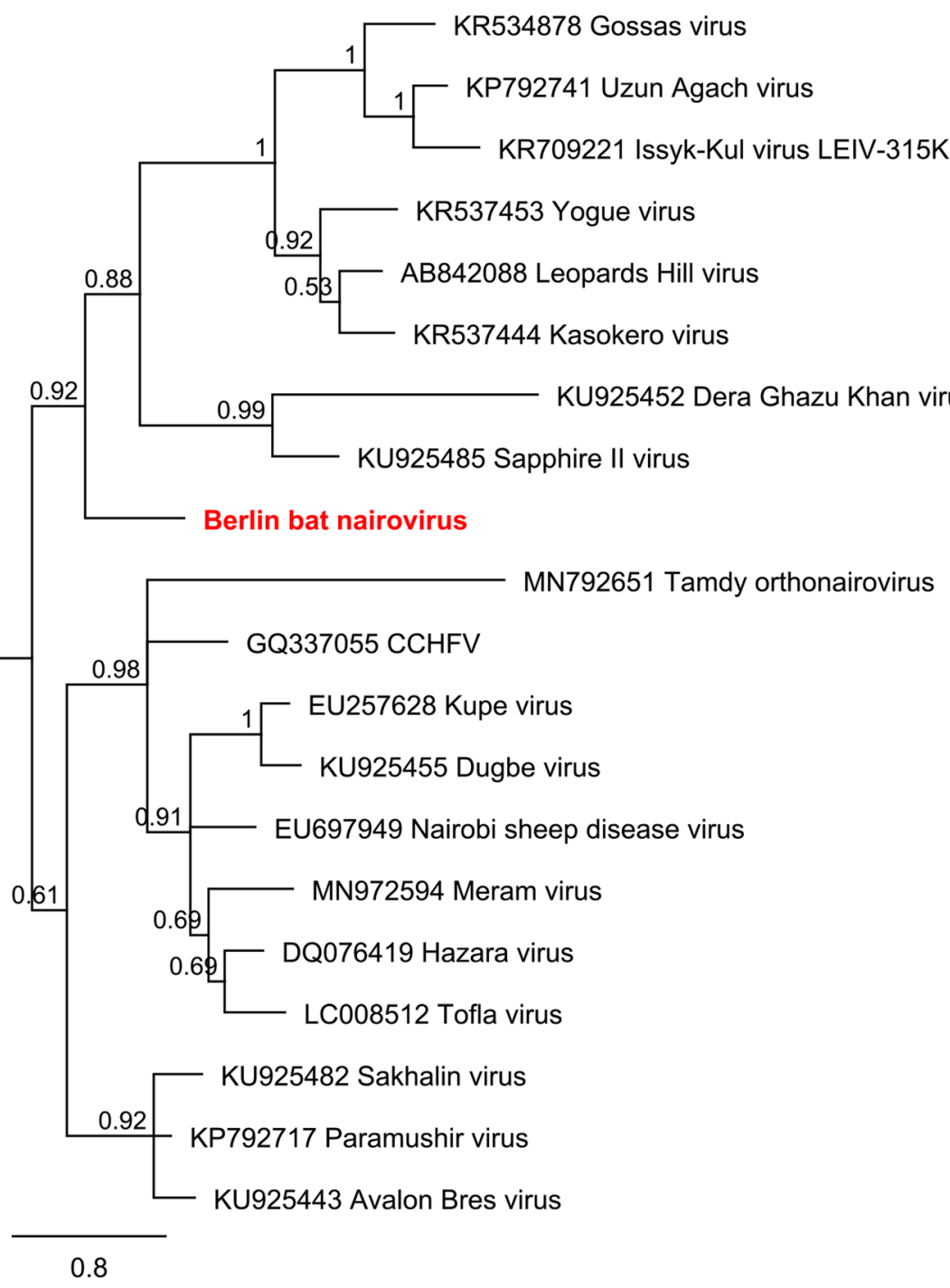

Figure 5. Phylogenetic reconstructions of Nairoviruses-2 ML, 1 million, $457 \mathrm{nt}$ of the L segment. Reconstruction was performed via the Bayesian MCMC approach using MrBayes with the following settings (burn-in, 30\%; frequency, 100; chain length, 1 million to 10 million, depending on when a standard derivation of below 0.025 was reached $)^{78}$. Hantaan virus was used as an outgroup. Reconstructed trees were visualized using FigTree and posterior probabilities were depicted for each node (http://tree.bio.ed.ac.uk/software/figtree/).

strain PbGER (ISKV PbGER) is further analyzed by whole genome sequencing as well as throughout analysis; this is the subject of another study ${ }^{45}$. Our findings show for the first time the abundance of this virus in Europe and within this species.

Sapphire II-like virus was detected in eleven Pipistrellus pipistrellus bats from pool 5 and confirmed predominantly in lung and spleen tissues (Supplementary Table S7). Phylogenetic reconstruction indicated that Sapphire II-like virus is related to Sapphire II virus and clusters with the Dera Ghazi Khan genogroup usually associated with birds ${ }^{41}$ (Fig. 5). Sapphire II virus was isolated from swallowed ticks in 1972 and was not reported to cause any diseases in humans ${ }^{46}$. This is the first description of this genotype in bats. We named the Sapphire II-like virus Berlin bat nairovirus (BbnV) after the origin of the corresponding bats.

Avalon Bres virus-like sequence was detected in Pipistrellus pipistrellus bats of pool 6 (Supplementary Table S8). Phylogenetically, Avalon Bres virus clusters monophyletically with the Sakhalin genogroup. Viruses of these genogroups have not been described before to be associated with bats. However, a serological study showed that several wild-caught bats had antibody responses to CCHFV proteins ${ }^{47}$. We named the Avalon Bres virus-like virus Wittenau bat nairovirus $(\mathrm{WbnV})$ after the origin of the corresponding bats.

Phenuivirus is a family within the order Bunyavirales ${ }^{40}$. The majority of the ten phenuivirus genera is mosquito-borne; however, some genera are transmitted by ticks (i.e. Banyangviruses) and are capable of causing severe diseases in humans and animals. Three phenuiviruses (genus phlebovirus) have been reported to be identified from bats: Malsoor virus, Rift Valley virus and Toscana virus ${ }^{42,43}$. Malsoor virus was isolated from Rousettus leschenaultii in India and is by phylogenetic reconstruction monophyletic with viruses of the genus 


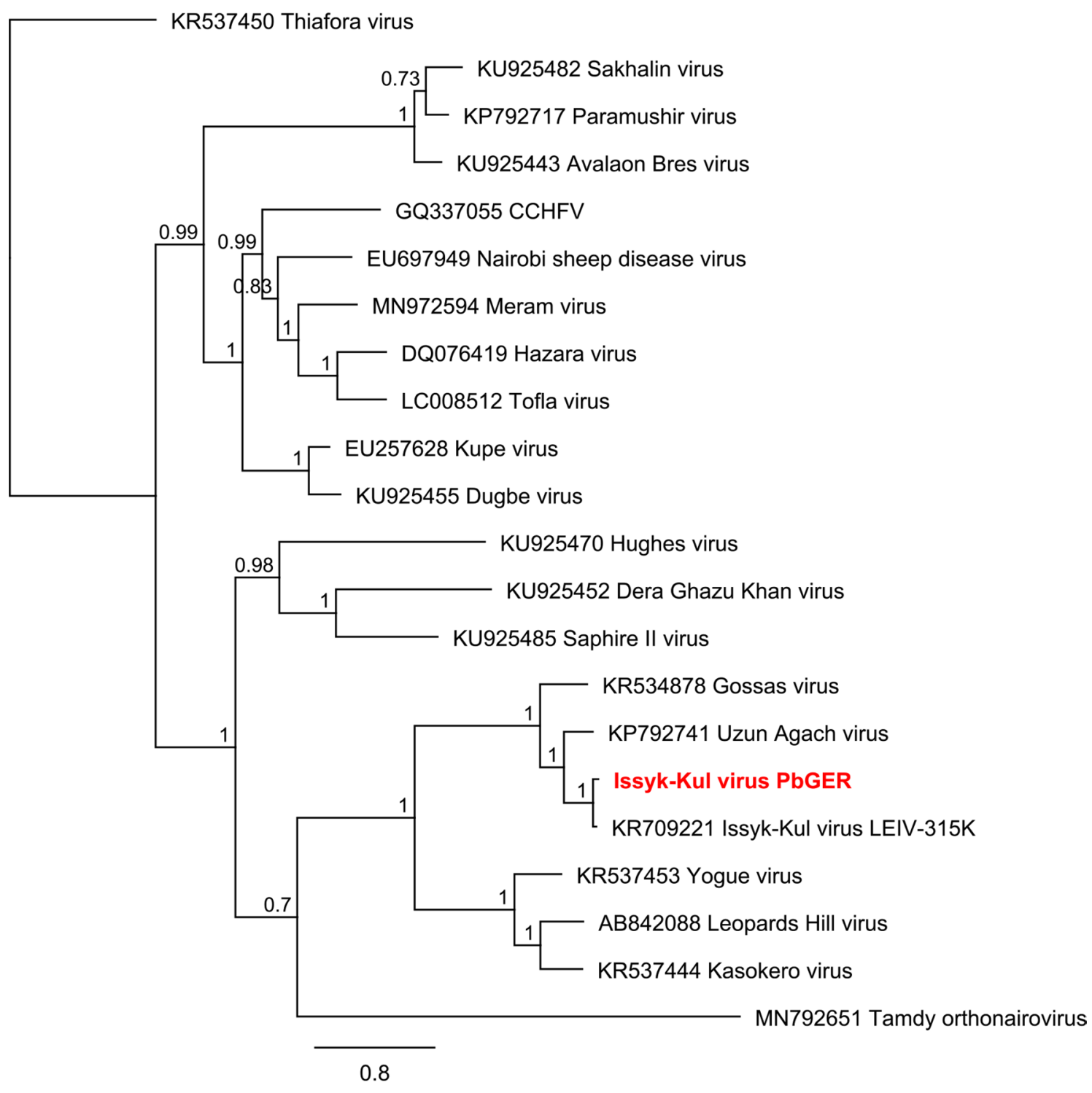

Figure 6. Phylogenetic reconstructions of Nairoviruses ML, 1 million, $1415 \mathrm{nt}$ of the L segment. Reconstruction was performed via the Bayesian MCMC approach using MrBayes with the following settings (burn-in, 30\%; frequency, 200; chain length, 1 million to 10 million, depending on when a standard derivation of below 0.025 was reached $)^{78}$. Hantaan virus was used as an outgroup. Reconstructed trees were visualized using FigTree and posterior probabilities were depicted for each node (http://tree.bio.ed.ac.uk/software/figtree/).

Banyangvirus, being related to Huaiyangshan banyangvirus (former SFTS) and Heartland virus which are capable of causing severe diseases in humans ${ }^{48}$. Here we describe the detection of three phenuiviruses related to Laurel Lake virus (Id 43\% aa) (genus Laulavirus) and Malsoor virus /SFTS (Id 70\% nt; 72\% aa) (genus Banyangvirus).

Six Eptesicus nilssonii bats from pool 3 were tested positive for Malsoor-like virus in liver, spleen, lungs and intestines (Supplementary Table S5). Phylogenetically, the Malsoor-like virus from Eptesicus nilssonii clusters monophyletically with the genus banyangvirus Huaiyangshan banyangvirus (SFTS) virus, Heartland virus and Malsoor virus (Fig. 7). This evolutionary distance could indicate a potential zoonotic transmission of both Malsoor virus and the found Malsoor-like virus to humans. We named the Malsoor-like virus Zwiesel bat banyangvirus (ZbbV) after the origin of the corresponding bats. The novel Zwiesel bat phlebovirus is further analyzed by whole genome sequencing as well as throughout analysis; this is the subject of another study published simultaneously as a spin-off to this study ${ }^{49}$.

Laurel Lake-like virus 1 and Laurel Lake-like virus 2 (genus Laulavirus) were identified in bats from pool 8 (Supplementary Table S10). Pool 8 comprises bats of two species, Pipistrellus nathusii and Plecotus aureus. Phylogenetic reconstruction of the Laurel Lake-like virus showed that Laurel Lake virus and Laurel Lake-like virus are quite distanced from the other viruses of the Uukuniemi group, although they are clearly clustering (Supplementary Fig. S3) ${ }^{50}$. We named the Laurel Lake-like virus 1 Bavarian bat lalavirus (BblV) after the origin of the corresponding bats. We named the Laurel Lake-like virus 2 Munich bat lalavirus (MblV) after the origin of the corresponding bats. 


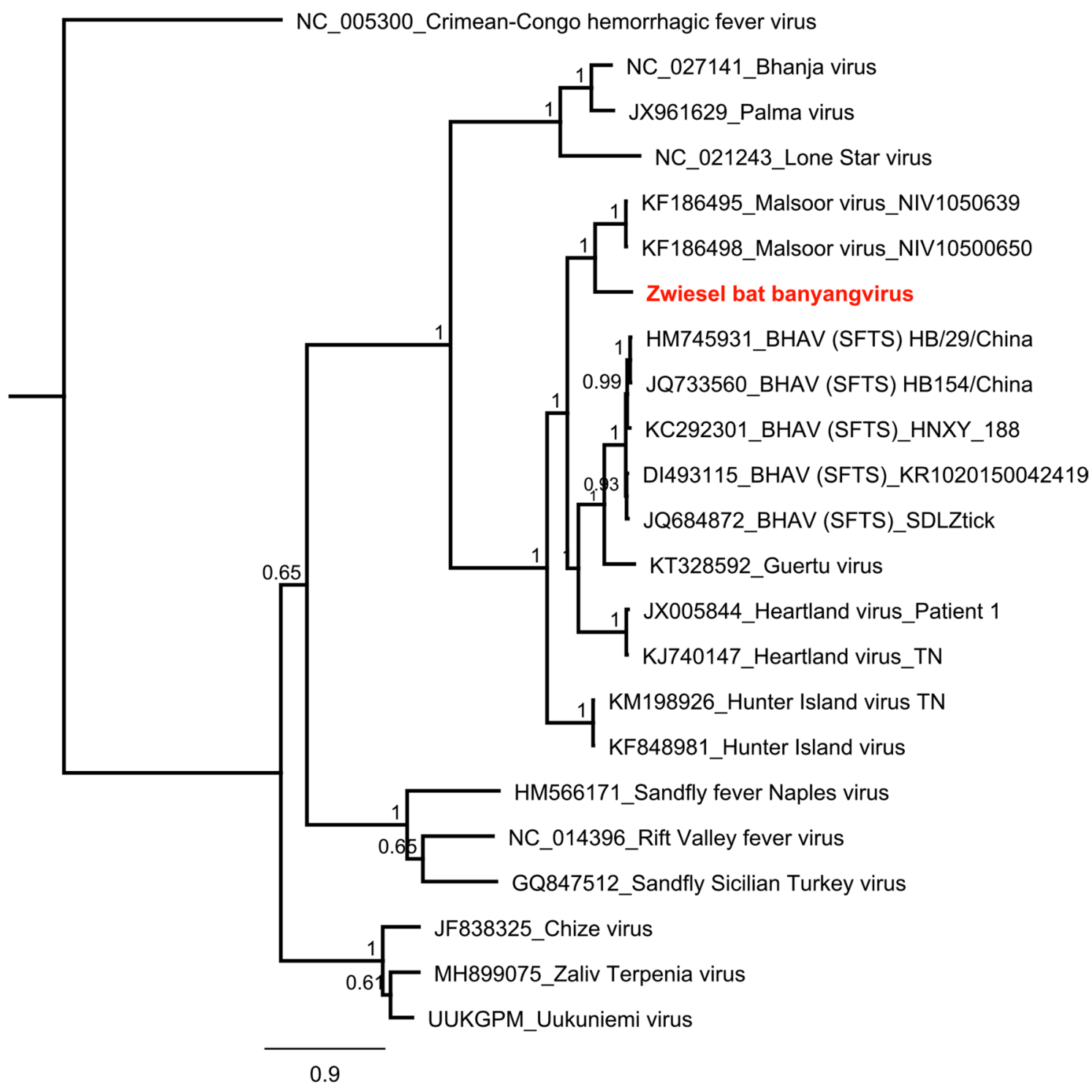

Figure 7. Phylogenetic reconstruction of Phenuiviruses glycoprotein-ML, 1 million, 2578 nt. Reconstruction was performed via the Bayesian MCMC approach using MrBayes with the following settings (burn-in, 30\%; frequency, 100; chain length, 1 million to 10 million, depending on when a standard derivation of below 0.025 was reached $)^{78}$. Reconstructed trees were visualized using FigTree and posterior probabilities were depicted for each node (http://tree.bio.ed.ac.uk/software/figtree/).

Three reovirus sequences (genera orbivirus, rotavirus and orthoreovirus) were identified in the virome data of pools 2, 5 and 8 (Supplementary Tables S4, S5 and S10). The orthoreovirus in pool 8 has been known before (T3/Bat/Germany/342/08) and served as a kind of positive control for this study, as we added the bat tissue from bat $342 / 08$, from which the virus was initially isolated, to the pool ${ }^{1}$ (Supplementary Table S10). The orbivirus and rotavirus are genera within the subfamily Sedoreovirinae of the family Reoviridae. The orbiviruses comprise several species that are inducing severe diseases in humans and animals (i.e. bluetongue disease or epizootic hemorrhagic disease virus) and are capable of replication in several arthropod and vertebrate hosts ${ }^{51}$. In pool 2 an orbivirus related to the yet unpublished Bat orbivirus from China (AccNo. MH144554.1) (Id 81\% aa) and Sathuvachari virus was identified in Nyctalus noctula bats (Supplementary Table S4) (Fig. 3). Sathuvachari virus has first been isolated in India in 1963, and because of its orbivirus character has tentatively been classified as mosquito-borne although the strain was isolated from a bird (starling) ${ }^{52}$. There have been two further orbiviruses identified from bats (Myotis rickettsi and Rhinolphus ferrumequinum) in China (Acc. No. KX343070.1 and KX161703.1). We named the Sathuvachari-like virus Irlbach bat orbivirus (IboV) after the origin of the corresponding bats.

The bat rotavirus identified in this study was detected in pool 5 which comprises tissues from Pipistrellus pipistrellus bats (Supplementary Table S7). Phylogenetic reconstruction allocates the bat rotavirus sequence into a distinct but related clade to rotaviruses type A (Id 58\% nt; 57\% aa) (Fig. 4). Numerous rotaviruses have been identified in bats but only one other rotavirus has been identified in European bats ${ }^{28}$. The bat rotavirus from France is similarly related to rotaviruses of group A. The zoonotic potential of these bat rotaviruses related to 
group A has yet to be determined. We named the rotavirus A-like virus Hannover bat rotavirus (HbrV) after the origin of the corresponding bats.

A sequence related to other members of the order Mononegavirales was identified in intestinal samples of Nyctalus noctula bats in pool 2 (Supplementary Table S4). It was described for these bats to have parasites in their intestines ${ }^{53}$; it is possible that the sequence originated from a tapeworm. On amino acid level the novel sequence shared highest similarity to Wenzhou tapeworm 1 virus (Id 35\% aa) and Midway virus ${ }^{54,55}$. Phylogenetically the strain was grouped distinct from Midway virus and was more closely related to Borna disease virus and rabies virus. The similarities on $n t$ level are quite low and the tree has to be interpreted with caution (SF2). However, these findings are interesting as bats are often discussed as potential reservoir host of many viruses of the order Mononegavirales (i.e. Ebola virus, Marburg virus, Nipah virus, Hendra virus and lyssaviruses). We named the Wenzhou tapeworm 1-like virus Berlin bat mononegavirus ( $\mathrm{BbmV}$ ) after the origin of the corresponding bats.

The screening of 375 bats with numerous family-specific PCRs resulted in several novel sequences (Table 2). The inoculation of the bat tissues into six different cell lines revealed two novel isolates (Supplementary Table S1). Virome sequencing of 189 histopathologically suspicious tissues of these bats resulted again in a high variety of novel virus sequences. Taking all of this into account, it is somewhat surprising to find different viruses in identical samples with these complementary approaches. However, the setup of the study design is insufficient to provide reliable statistics. For the RNA virus screening the organ material was homogenized in RNAlater ${ }^{\circledR}$ buffer and $30 \mu \mathrm{l}$ per organ were pooled before extraction. For the DNA virus screening $30 \mu \mathrm{l}$ of each organ natively frozen at $-80^{\circ} \mathrm{C}$ was pooled before extraction. Cell culture isolation was also done with the native samples, although on differing cell culture systems. However, in cell culture only the occurrence of a visible $\mathrm{CPE}$ gives a clue of an ongoing virus infection and the absence of $\mathrm{CPE}$ does not exclude the potential infection. For the virome sequencing only those individual organs (native $-80^{\circ} \mathrm{C}$ ) were used that showed alterations in histopathology. If family-specific PCRs resulted in clear amplification and revealed a novel virus sequence after Sanger sequencing, one would expect to be able to obtain sequences of the same virus by virome sequencing of the same sample. In fact, many of the organ bat tissues that were prepared for virome sequencing also revealed positive results in family-specific PCRs. For example, Bat E95/09 (Supplementary Table S7) was tested positive for paramyxoviruses by $\mathrm{PCR}^{32}$. The respective tissues were subjected to virus purification and virome sequencing within pool 4, but no paramyxoviruses were detected in the virome data. A possible explanation could be that the purification method we have used, TUViD-VM, did not sufficiently purify paramyxoviruses from tissues; but this is exactly what this protocol was designed for ${ }^{10}$. Actually, the whole protocol was validated and tested with a range of viruses (i.e. paramyxovirus, poxvirus, influenza virus and reovirus), with the most remarkable results from paramyxovirus (Sendai virus) ${ }^{10}$. In addition, we have tested the reproducibility and consistency of the TUViD-VM protocol numerous times and found it to be very stable ${ }^{56}$. Furthermore, it has to be considered that we have used pooled tissues for our examinations instead of i.e. single organs. It is possible that this may have affected the detectability of the different viruses. However, we have used pooled tissues for all methods compared and therefore results should be comparable. Taking this into account, we propose that nothing is more important in virome studies than the ratio between targeted and untargeted sequences. For instance, if we apply a family-specific PCR to a mixture of cDNA containing 100 genome equivalents of the targeted paramyxovirus, we will most probably be able to obtain a clean and sufficient amplification of the targeted sequences, although the cDNA contains only the 100 genome equivalents of paramyxovirus over millions of other sequences. In comparison, the approach of virome sequencing differs significantly. When millions of other sequences compete (e.g. host genome) the likelihood of detection of an underrepresented number of viral sequences would be very low. To address and circumvent this obvious fact, the TUViD-VM protocol was applied in this study, as it aims to decrease the amount of background (host) sequences and amplify the viral sequences to increase the detection ratio and likelihood. One accompanying effect we observed was that high numbers of viral reads of other viruses (i.e. more than 900,000 reads for picornaviruses in pool 5) impeded the sequencing of low amounts of other viral amplicons. Similarly, the analyses of PCR-negative results revealed a surprising outcome. All bats were screened for the presence of bunyaviral sequences, especially for phenuiviruses and nairoviruses, by family-specific PCR with negative results. Interestingly, virome sequencing revealed the presence of six novel strains of bunyaviruses with identities ranging from 70 to 95 percent identity on nt level to known virus sequences.

This leads to the conclusion that the outcome of virus discovery studies, whether approached by PCR, metagenomics or cell culture, provides only a fraction of the viruses truly present in a sample. The methods should be used complementarily to give a more complete picture of virus diversity rather than to replace each other-as has often been described for the advantages of metagenomics over classic PCR approaches. The combined data of existing individual studies investigated by different virus discovery protocols with their conclusions are further used to extrapolate and predict outbreak risks and hotspots. As long as we use single virus detection protocols in studies only, the very true diversity of viruses will stay hidden, unrecognized by our insufficient methodological approaches. It might be time for common approaches, where scientists doing virus discovery and modeling work join forces and design studies in a more comparable and meaningful manner.

\section{Methods}

Study. In compliance with the species protection through the European Commission (https://ec.europa.eu/ environment/nature/legislation/habitatsdirective/) and the Agreement on the Conservation of Populations of European Bats (www.eurobats.org), investigative research on bats was permitted by local government bodies ${ }^{38}$. We named the manuscript Virome of German Bats as the bats were found in Germany. However, bats are migrating animals, many of them covering long distances throughout Europe. Therefore, our results could also be expected in other parts of Europe. We herewith confirm that all permits to investigate carcasses of deceased bats and all experimental protocols on the dead bats were approved by the respective local governmental authori- 

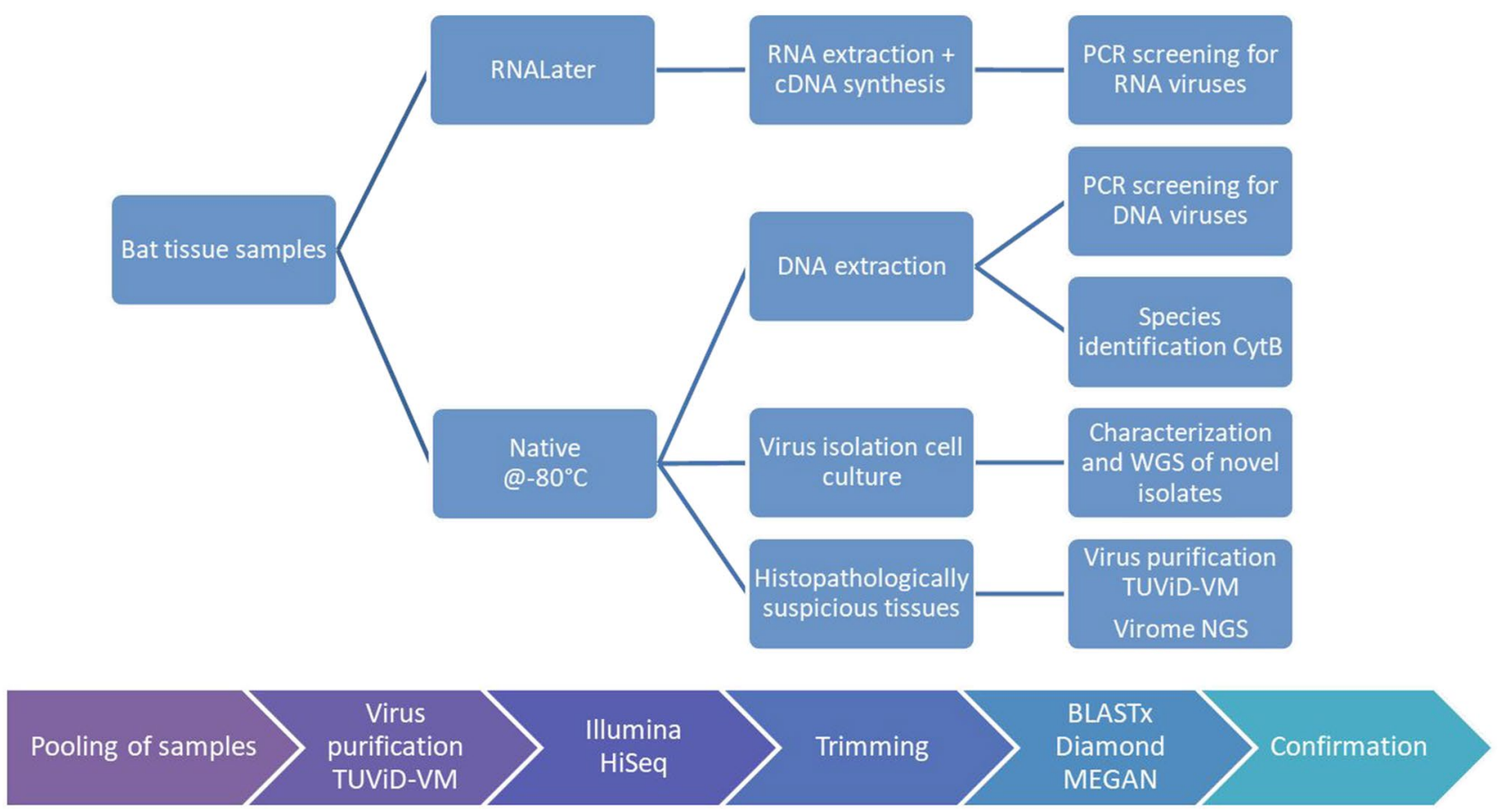

Figure 8. Workflow. The workflow of sample preparation and analysis is depicted.

ties (district government of Upper Bavaria, Munich [No. 55.1-8642.1-4-2006]; district government of Bavarian Swabia, Augsburg [No. 51-8645.11/489]; Lower Saxony water management, coastal defense and nature conservation, Hanover [No. 897.21-20] and senate department for urban development and the environment, Berlin [No. I E 222-10.04.2004]). We herewith further confirm that all experiments were performed in accordance with relevant guidelines and regulations. As part of a study on diseases in native bats ${ }^{38}, 375$ bats of 18 vespertilionid bat species were examined (Myotis mystacinus [ $\mathrm{n}=37]$, . daubentonii $[\mathrm{n}=17]$, M. bechsteinii $[\mathrm{n}=1], M$. brandtii $[\mathrm{n}=2]$, M. myotis [n=5], M. nattereri $[\mathrm{n}=9]$, Pipistrellus pipistrellus [n=9698], P. nathusii $[\mathrm{n}=28], P$. kuhlii $[\mathrm{n}=8]$, P. pygmaeus [n=3], Vespertilio murinus $[\mathrm{n}=20]$, Barbastella barbastellus $[\mathrm{n}=2]$, Plecotus austriacus $[\mathrm{n}=1]$, Plecotus auritus $[\mathrm{n}=20]$, Eptesicus nilssonii $[\mathrm{n}=15]$, E. serotinus $[\mathrm{n}=20]$, Nyctalus noctula $[\mathrm{n}=86]$ and N. leisleri $[\mathrm{n}=3]$ ). Animals were found dead, injured or moribund near roosting sites or human habitations ${ }^{38}$ in urban and suburban areas of different regions in Italy $(n=1)$ and Germany $(n=374)$ (Bavaria $[n=150]$, Lower Saxony $[n=35]$ and Berlin greater metropolitan area $[n=148]$, Brandenburg $[n=36]$, Baden Wuerttemberg $[n=3])$. All bat carcasses were kindly provided by bat researchers and bat rehabilitation centers from the different geographic regions. In case bats died in care or had to be euthanized for medical reasons, the carcasses were handled as described before ${ }^{38,57-59}$. Aliquots of the individual organs were divided between two tubes: one tube with RNAlater ${ }^{\circledR}$ (Qiagen, Hilden, Germany) for RNA extraction and one tube native frozen at $-80^{\circ} \mathrm{C}$ and sent to the Robert Koch Institute for virological examination (Fig. 8).

All work was performed at Biosafety level-2 conditions with appropriate precautions. The study was divided into three methodological sections. (1) PCR screening, (2) Virus isolation via cell culture and (3) Virome analysis. Every section had its own difficulties and individual steps for sample preparation explained in the following.

PCR screening for RNA viruses. $30 \mu \mathrm{l}$ of each of the eight individual organ homogenates (in RNAlater ${ }^{\circledR}$ ) of one respective bat were pooled (lungs, liver, spleen, heart, brain, salivary gland, intestine and kidney). RNA extraction from RNAlater ${ }^{\circledR}$-stabilized samples and cDNA synthesis was performed as described before ${ }^{32}$. The pool containing $240 \mu \mathrm{l}$ of organ homogenate was then extracted using the PureLinkTM Viral RNA/DNA Mini Kit (Invitrogen, Carlsbad, USA). Extracted RNA was transcribed to cDNA by using the TaqMan ${ }^{\circledR}$ Reverse Transcription Reagents (Applied Biosystems, Darmstadt, Germany). The cDNA pools of 375 bats were screened by differing family-specific PCR systems for the detection of paramyxoviruses ${ }^{60}$, arenaviruses ${ }^{61}$, coronaviruses $^{35}$, filoviruses $^{62}$, flaviviruses ${ }^{63}$, hantaviruses ${ }^{64}$, nairo- and phleboviruses ${ }^{65}$ and influenza viruses ${ }^{66}$.

PCR screening for DNA viruses. $30 \mu \mathrm{l}$ of each of the eight individual organ homogenates (native frozen at $-80^{\circ} \mathrm{C}$ ) of one respective bat were pooled (lungs, liver, spleen, heart, brain, salivary gland, intestine, kidney). DNA was extracted using the PureLinkTM Viral RNA/DNA Mini Kit (Invitrogen) as described before ${ }^{31,33}$. The DNA pools of 375 bats were screened by differing family-specific PCR systems for the detection of adenoviruses ${ }^{67}$, herpesviruses ${ }^{68}$ and poxviruses ${ }^{69,70}$. 


\begin{tabular}{|c|c|c|c|}
\hline Pool & \# bats & Species (individuals per species) & Organs \\
\hline \multirow{6}{*}{1} & \multirow{6}{*}{12} & Myotis bechsteinii (1) & S \\
\hline & & Myotis nattereri (3) & L, I, S, SG \\
\hline & & Myotis myotis (3) & L, I \\
\hline & & Nyctalus leisleri (1) & $\mathrm{L}$ \\
\hline & & Barbastella barbastellus (1) & $\mathrm{L}$ \\
\hline & & Pipistrellus kuhlii (3) & $\mathrm{L}$ \\
\hline 2 & 22 & Nyctalus noctula (22) & L, I, S, H, \\
\hline 3 & 12 & Eptesicus nilssonii (12) & $\mathbf{L}, \mathbf{I}, \mathbf{S}, \mathrm{H}, \mathrm{Li}, \mathrm{B}$ \\
\hline 4 & 11 & Myotis mystacinus (11) & $\mathbf{L}, \mathbf{S}, \mathrm{Li}, \mathrm{K}$ \\
\hline 5 & 12 & Pipistrellus pipistrellus (12) & L, I, S, Li, K \\
\hline \multirow{2}{*}{6} & \multirow{2}{*}{24} & Pipistrellus pipistrellus (23) & L, I, S, SG, H, Li, K \\
\hline & & Pipistrellus pygmaeus (1) & L, S \\
\hline 7 & 6 & Eptesicus serotinus (6) & $\mathbf{L}, \mathbf{I}, \mathbf{S}, \mathrm{H}, \mathrm{Li}, \mathrm{K}$ \\
\hline \multirow{2}{*}{8} & \multirow{2}{*}{11} & Plecotus aureus (7) & L, I, S, H, Li \\
\hline & & Pipistrellus nathusii (4) & L, I, S, Li \\
\hline \multirow{2}{*}{9} & \multirow{2}{*}{11} & Myotis daubentonii (5) & L, S, SG \\
\hline & & Vespertilio murinus (6) & L, S, SG, Li \\
\hline$\Sigma$ & 118 & 16 species & 189 organs \\
\hline
\end{tabular}

Table 5. Composition of bat pools. Table summarizes species and organs for the nine individual pools used for metagenomics sequencing and cell culture isolation. Organs written in bold have the highest percentage in the individual pool. \# number, $L$ lung, $I$ intestine, $S$ spleen, $S G$ salivary gland, $H$ heart, $L i$ liver, $K$ kidney, $B$ brain.

Virus isolation in cell culture. Virus isolation in cell culture was performed from pools containing all eight individual organs of the respective bats natively frozen at $-80^{\circ} \mathrm{C}$ as described before ${ }^{30,31}$. For cell culture isolation different cell culture systems were used; these are listed in Supplementary Table S1.

Virome sequencing. Selected single organs (native frozen at $-80^{\circ} \mathrm{C}$ ) of 118 of the 375 individual bats were subjected to further investigation. These 118 bats and their corresponding 189 native frozen organ tissues were chosen by analysis of the pathological findings ${ }^{71}$. Several bats were found to have alterations that may be related to viral infections (e.g., interstitial pneumonia, pulmonary BALT hyperplasia, infiltrates of mononuclear cells in different organs, diffuse enlarged villi and mononuclear intestinal cell infiltrates or catarrhal or hemorrhagic enteritis). Due to the large number of individual samples, organs were allocated to nine pools for virus purification with TUViD-VM and sequencing ${ }^{10}$. Pools were established using the following criteria: (a) Pools should consist of similar sample numbers, (b) Pools should have only one bat species and (c) If number of bats is not sufficient to build a single pool, species are mixed. Table 5 and Fig. 9 summarize the composition of these nine individual pools.

$200 \mu \mathrm{l}$ of each individual organ from the 118 bats was pooled into nine differing pools, depending on histopathological results and according to the species. The composition of the individual pools is given in Table 5. Each of the nine pools was divided for inoculation onto Vero and Paki cell cultures for virus isolation as described before $^{72,73}$. The original TUViD-VM purification protocol used in this study comprises the following steps: (1) homogenization, (2) clearing centrifugation, (3) ultracentrifugation through sucrose cushion, (4) ultracentrifugation, (5) digestion, (6) extraction, (7) cDNA and double strand synthesis and (8) random amplification and size selection via agarose gel electrophoresis ${ }^{10}$. Instead of using $200 \mu \mathrm{l}$ of tissue homogenate as prescribed in the original protocol, $3 \mathrm{ml}$ of organ tissue was used and the protocol was upscaled with small modifications ${ }^{10}$ : in most pools the homogenate volume exceeded $3 \mathrm{ml}$; however, in case the amount of homogenate was too low, the volume was adapted with PBS to $3 \mathrm{ml}$; for ultracentrifugation, the rotors and pace were adapted accordingly by using the SW32 rotor (Beckman Coulter, Krefeld, Germany) also for the first ultracentrifugation step. From step (4) of the original TUViD-VM protocol onward, the protocol was performed without any further modifications.

After size selection by excision of the area between 500 and $1000 \mathrm{nt}$ following agarose gel electrophoresis, samples were prepared for sequencing. Libraries were built using the NexteraXT protocol as described before ${ }^{10}$. The sequencing reaction was performed on the Illumina HiSeq Sequencer in high throughput mode using 150 cycles.

Raw data was processed as follows (Fig. 8): Adapters were trimmed and filtering of read length and quality was performed. Raw reads were then subtractive mapped against customized databases to remove background reads (bacteria and mammalian genomes). Remaining reads were assembled to contigs using Velvet ${ }^{74}$. Contigs were then compared to the viral protein database ( $\mathrm{nr}$ NCBI) via the DIAMOND tool and results were visualized in MEGAN6 (-sensitive) ${ }^{37,38}$. Selected results from MEGAN6 were blasted using BLASTx on the NCBI GenBank database. Full genomes (if available) of the most similar sequences were downloaded to serve as a reference. The initial trimmed reads were then mapped to the reference sequence using Bowtie 2 to identify more matching reads and check the correct allocation visually for quality ${ }^{75}$. Virus genomes were also assembled using Bowtie 2 . Sequences were checked for plausibility by analyzing the closest related virus. In the case of i.e. retroviruses 


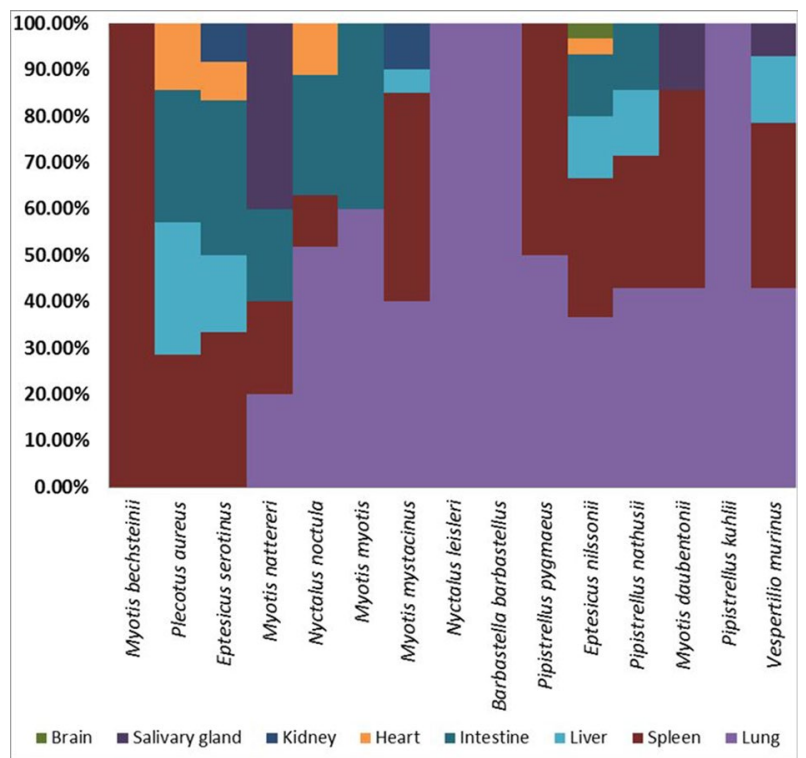

Figure 9. Percentage of individual organs pooled per species is depicted.

the closest related sequences were also from bat species, proving that they are possible to occur. Sequences of highest interest were extended by spanning PCRs and primer walking followed by Sanger sequencing. For all sequences of interest specific primers were designed to confirm the sequences in CDNA by conventional PCR of the individual extracted pools and organ samples eventually. Cycling conditions and primers are available on request. Any bands of targeted height were purified, Sanger sequenced and compared to the original sequence obtained from Next Generation Sequencing (NGS).

Final sequences obtained from data analysis and Sanger sequencing were used to reconstruct phylogenetic trees. Sequences were aligned to type species (whenever possible) of the respective viral family (ICTV database) and other related viruses of interest via ClustalW. Alignment quality was checked with the online tool T-Coffee ${ }^{76}$. Model of evolution was predicted via jmodeltest and the model with the best AIC score was picked ${ }^{77}$. The actual reconstruction was performed via the Bayesian MCMC approach using MrBayes with the following settings (burn-in, 30\%; frequency, 100; chain length, 1 million to 10 million depending on when a standard derivation of below 0.025 was reached $)^{78}$. Reconstructed trees were visualized using FigTree and posterior probabilities were depicted for each node (http://tree.bio.ed.ac.uk/software/figtree/).

Received: 31 October 2019; Accepted: 15 March 2021

Published online: 01 April 2021

\section{References}

1. Calisher, C. H., Childs, J. E., Field, H. E., Holmes, K. V. \& Schountz, T. Bats: Important reservoir hosts of emerging viruses. Clin. Microbiol. Rev. 19, 531-545 (2006).

2. Halpin, K., Young, P. L., Field, H. E. \& Mackenzie, J. S. Isolation of Hendra virus from pteropid bats: A natural reservoir of Hendra virus. J. Gen. Virol. 81, 1927-1932 (2008).

3. Towner, J. S. et al. Isolation of genetically diverse Marburg viruses from Egyptian fruit bats. PLoS Pathog. 5, e1000536 (2009).

4. Li, W. et al. Bats are natural reservoirs of SARS-like coronaviruses. Science 310, 676-679 (2005).

5. Enserink, M. Emerging diseases. Malaysian researchers trace Nipah virus outbreak to bats. Science 289, 518-519 (2000).

6. Teeling, E. C. et al. A molecular phylogeny for bats illuminates biogeography and the fossil record. Science 307, 580-584 (2005).

7. Ng, J. H. J., Tachedjian, M., Wang, L. F. \& Baker, M. L. Insights into the ancestral organisation of the mammalian MHC class II region from the genome of the pteropid bat, Pteropus alecto. BMC Genom. 18, 388 (2017).

8. Ng, J. H. et al. Evolution and comparative analysis of the bat MHC-I region. Sci. Rep. 6, 21256 (2016).

9. Zhang, G. et al. Comparative analysis of bat genomes provides insight into the evolution of flight and immunity. Science 339, 456-460 (2013).

10. Kohl, C. et al. Protocol for metagenomic virus detection in clinical specimens. Emerg. Infect. Dis. 21, 48-57 (2015).

11. Thurber, R. V., Haynes, M., Breitbart, M., Wegley, L. \& Rohwer, F. Laboratory procedures to generate viral metagenomes. Nat. Protoc. 4, 470-483 (2009).

12. Hall, R. J. et al. Evaluation of rapid and simple techniques for the enrichment of viruses prior to metagenomic virus discovery. J. Virol. Methods 195, 194-204 (2014).

13. Baker, K. S. et al. Metagenomic study of the viruses of African straw-coloured fruit bats: Detection of a chiropteran poxvirus and isolation of a novel adenovirus. Virology 441, 95-106 (2013).

14. Yuan, L. et al. Evidence for retrovirus and paramyxovirus infection of multiple bat species in China. Viruses 6, 2138-2154 (2014).

15. Ge, X. et al. Metagenomic analysis of viruses from bat fecal samples reveals many novel viruses in insectivorous bats in China. J. Virol. 86, 4620-4630 (2012).

16. Wang, J. et al. Discovery of novel virus sequences in an isolated and threatened bat species, the New Zealand lesser short-tailed bat (Mystacina tuberculata). J. Gen. Virol. 96, 2442-2452 (2015).

17. Tse, H. et al. Identification of a novel bat papillomavirus by metagenomics. PLoS ONE 7, e43986 (2012). 
18. Li, L. et al. Bat guano virome: Predominance of dietary viruses from insects and plants plus novel mammalian viruses. J. Virol. 84, 6955-6965 (2010).

19. Wu, Z. et al. Deciphering the bat virome catalog to better understand the ecological diversity of bat viruses and the bat origin of emerging infectious diseases. ISME J. 10, 609-620 (2016).

20. Donaldson, E. F. et al. Metagenomic analysis of the viromes of three North American bat species: Viral diversity among different bat species that share a common habitat. J. Virol. 84, 13004-13018 (2010).

21. Salmier, A. et al. Virome analysis of two sympatric bat species (Desmodus rotundus and Molossus molossus) in French Guiana. PLoS ONE 12, e0186943 (2017).

22. Wu, Z. et al. Virome analysis for identification of novel mammalian viruses in bat species from Chinese provinces. J. Virol. 86, 10999-11012 (2012).

23. Yinda, C. K. et al. A single bat species in Cameroon harbors multiple highly divergent papillomaviruses in stool identified by metagenomics analysis. Virol. Rep. 6, 74-80 (2016).

24. Zheng, X. Y. et al. Viral metagenomics of six bat species in close contact with humans in southern China. Arch. Virol. 163, 73-88 (2017).

25. Yinda, C. K. et al. Novel highly divergent sapoviruses detected by metagenomics analysis in straw-colored fruit bats in Cameroon. Emerg. Microbes Infect. 6, e38 (2017).

26. He, B. et al. Virome profiling of bats from Myanmar by metagenomic analysis of tissue samples reveals more novel mammalian viruses. PLoS ONE 8, e61950 (2013).

27. Hu, D. et al. Virome analysis for identification of novel mammalian viruses in bats from Southeast China. Sci. Rep. 7, 10917 (2017).

28. Dacheux, L. et al. A preliminary study of viral metagenomics of French bat species in contact with humans: Identification of new mammalian viruses. PLoS ONE 9, e87194 (2014).

29. Chen, L., Liu, B., Yang, J. \& Jin, Q. DBatVir: The database of bat-associated viruses. Database 2014, bau021 (2014).

30. Kohl, C. et al. Isolation and characterization of three mammalian orthoreoviruses from European bats. PLoS ONE 7, e43106 (2012).

31. Kohl, C. et al. Genome analysis of bat adenovirus 2: Indications of interspecies transmission. J. Virol. 86, 1888-1892 (2012).

32. Kurth, A. et al. Novel paramyxoviruses in free-ranging European bats. PLoS ONE 7, e38688 (2012).

33. Vidovszky, M. et al. Random sampling of the Central European bat fauna reveals the existence of numerous hitherto unknown adenoviruses. Acta Vet. Hung. 63, 508-525 (2015).

34. Wibbelt, G. et al. Discovery of herpesviruses in bats. J. Gen. Virol. 88, 2651-2655 (2007).

35. de Souza Luna, L. K. et al. Generic detection of coronaviruses and differentiation at the prototype strain level by reverse transcription-PCR and nonfluorescent low-density microarray. J. Clin. Microbiol. 45, 1049-1052 (2007).

36. Sonntag, M., Muhldorfer, K., Speck, S., Wibbelt, G. \& Kurth, A. New adenovirus in bats, Germany. Emerg. Infect. Dis. 15, 2052-2055 (2009).

37. Huson, D. H., Auch, A. F., Qi, J. \& Schuster, S. C. MEGAN analysis of metagenomic data. Genome Res. 17, 377-386 (2007).

38. Buchfink, B., Xie, C. \& Huson, D. H. Fast and sensitive protein alignment using DIAMOND. Nat. Methods 12, 59-60 (2015).

39. Rosseel, T., Pardon, B., De Clercq, K., Ozhelvaci, O. \& Van Borm, S. False-positive results in metagenomic virus discovery: A strong case for follow-up diagnosis. Transbound. Emerg. Dis. 61, 293-299 (2014).

40. Blitvich, B. et al. Bunyavirus taxonomy: Limitations and misconceptions associated with the current ICTV criteria used for species demarcation. Am. J. Trop. Med. Hyg. 99, 11-16 (2018).

41. Walker, P. J. et al. A global genomic characterization of nairoviruses identifies nine discrete genogroups with distinctive structural characteristics and host-vector associations. Am. J. Trop. Med. Hyg. 94, 1107-1122 (2016).

42. Lvov, D. K. et al. "Issyk-Kul" virus, a new arbovirus isolated from bats and Argas (Carios) vespertilionis (Latr., 1802) in the Kirghiz S.S.R. Brief report. Arch. Gesamte Virusforsch. 42, 207-209 (1973).

43. Atkinson, B., Marston, D. A., Ellis, R. J., Fooks, A. R. \& Hewson, R. Complete genomic sequence of Issyk-Kul virus. Genome Announc. 3, e00662-e715 (2015).

44. L'Vov, D. K., Kostiukov, M. A., Daniiarov, O. A., Tukhtaev, T. M. \& Sherikov, B. K. Outbreak of arbovirus infection in the Tadzhik SSR due to the Issyk-Kul virus (Issyk-Kul fever). Vopr. Virusol. 29, 89-92 (1984).

45. Brinkmann, A. et al. First detection of bat-borne Issyk-Kul virus in Europe. Sci. Rep. 10, 22384 (2020).

46. Mahy, B. W. J. The Dictionary of Virology 4 th edn. (Academic Press, 2009).

47. Muller, M. A. et al. Evidence for widespread infection of African bats with Crimean-Congo hemorrhagic fever-like viruses. Sci. Rep. 6, 26637 (2016).

48. Mourya, D. T. et al. Malsoor virus, a novel bat phlebovirus, is closely related to severe fever with thrombocytopenia syndrome virus and heartland virus. J. Virol. 88, 3605-3609 (2014).

49. Kohl, C. et al. Zwiesel bat banyangvirus, a potentially zoonotic Huaiyangshan banyangvirus (formerly known as SFTS)-like banyangvirus in Northern bats from Germany. Sci. Rep. 10, 1370 (2020).

50. Tokarz, R. et al. Identification of novel viruses in Amblyomma americanum, Dermacentor variabilis, and Ixodes scapularis ticks. mSphere 3, e00614-e617. https://doi.org/10.1128/mSphere.00614-17 (2017).

51. Day, J. M. The diversity of the orthoreoviruses: molecular taxonomy and phylogentic divides. Infect. Genet. Evol. 9, 390-400 (2009).

52. Kapoor, A. et al. A novel mosquito-borne Orbivirus species found in South-east Asia. J. Gen. Virol. 94, 1051-1057 (2013).

53. Mühldorfer, K. et al. Diseases and causes of death in European bats: Dynamics in disease susceptibility and infection rates. PLoS ONE 6, e29773 (2011).

54. Shi, M. et al. Redefining the invertebrate RNA virosphere. Nature 540, 539-543 (2016).

55. Takahashi, M. et al. Isolation and characterization of midway virus: A new tick-borne virus related to Nyamanini. J. Med. Virol. 10, 181-193 (1982).

56. Kohl, C., Wegener, M., Nitsche, A. \& Kurth, A. Use of RNALater((R)) preservation for virome sequencing in outbreak settings. Front. Microbiol. 8, 1888 (2017).

57. Muhldorfer, K., Schwarz, S., Fickel, J., Wibbelt, G. \& Speck, S. Genetic diversity of Pasteurella species isolated from European vespertilionid bats. Vet. Microbiol. 149, 163-171 (2011).

58. Muhldorfer, K., Wibbelt, G., Haensel, J., Riehm, J. \& Speck, S. Yersinia species isolated from bats, Germany. Emerg. Infect. Dis. 16, $578-580$ (2010).

59. Muhldorfer, K., Speck, S. \& Wibbelt, G. Proposal of Vespertiliibacter pulmonis gen. nov., sp. Nov. and two genomospecies as new members of the family Pasteurellaceae isolated from European bats. Int. J. Syst. Evol. Microbiol. 64, 2424-2430 (2014).

60. Tong, S., Chern, S. W., Li, Y., Pallansch, M. A. \& Anderson, L. J. Sensitive and broadly reactive reverse transcription-PCR assays to detect novel paramyxoviruses. J. Clin. Microbiol. 46, 2652-2658 (2008).

61. Vieth, S. et al. RT-PCR assay for detection of Lassa virus and related Old World arenaviruses targeting the L gene. Trans. R Soc. Trop. Med. Hyg. 101, 1253-1264 (2007).

62. Zhai, J. et al. Rapid molecular strategy for filovirus detection and characterization. J. Clin. Microbiol. 45, 224-226 (2007).

63. Sanchez-Seco, M. P. et al. Generic RT-nested-PCR for detection of flaviviruses using degenerated primers and internal control followed by sequencing for specific identification. J. Virol. Methods 126, 101-109 (2005).

64. Klempa, B. et al. Hantavirus in African wood mouse, Guinea. Emerg. Infect. Dis. 12, 838-840 (2006). 
65. Lambert, A. J. \& Lanciotti, R. S. Consensus amplification and novel multiplex sequencing method for S segment species identification of 47 viruses of the Orthobunyavirus, Phlebovirus, and Nairovirus genera of the family Bunyaviridae. J. Clin. Microbiol. 47, 2398-2404 (2009).

66. Schulze, M., Nitsche, A., Schweiger, B. \& Biere, B. Diagnostic approach for the differentiation of the pandemic influenza A(H1N1) $\mathrm{v}$ virus from recent human influenza viruses by real-time PCR. PLoS ONE 5, e9966 (2010).

67. Wellehan, J. F. et al. Detection and analysis of six lizard adenoviruses by consensus primer PCR provides further evidence of a reptilian origin for the atadenoviruses. J. Virol. 78, 13366-13369 (2004).

68. Ehlers, B. et al. Detection of new DNA polymerase genes of known and potentially novel herpesviruses by PCR with degenerate and deoxyinosine-substituted primers. Virus Genes 18, 211-220 (1999).

69. Schroeder, K. \& Nitsche, A. Multicolour, multiplex real-time PCR assay for the detection of human-pathogenic poxviruses. Mol. Cell. Probes 24, 110-113 (2010).

70. Li, Y., Meyer, H., Zhao, H. \& Damon, I. K. GC content-based pan-pox universal PCR assays for poxvirus detection. J. Clin. Microbiol. 48, 268-276 (2010).

71. Muhldorfer, K., Speck, S. \& Wibbelt, G. Diseases in free-ranging bats from Germany. BMC Vet. Res. 7, 61 (2011).

72. Kohl, C. et al. Hervey virus: Study on co-circulation with Henipaviruses in Pteropid bats within their distribution range from Australia to Africa. PLoS ONE 13, e0191933 (2018).

73. Barr, J. et al. Isolation of multiple novel paramyxoviruses from pteropid bat urine. J. Gen. Virol. 96, 24-29 (2015).

74. Zerbino, D. R. \& Birney, E. Velvet: Algorithms for de novo short read assembly using de Bruijn graphs. Genome Res. 18, 821-829 (2008).

75. Langmead, B., Trapnell, C., Pop, M. \& Salzberg, S. L. Ultrafast and memory-efficient alignment of short DNA sequences to the human genome. Genome Biol. 10, R25 (2009).

76. Notredame, C., Higgins, D. G. \& Heringa, J. T-Coffee: A novel method for fast and accurate multiple sequence alignment. J. Mol. Biol. 302, 205-217 (2000).

77. Darriba, D., Taboada, G. L., Doallo, R. \& Posada, D. jModelTest 2: More models, new heuristics and parallel computing. Nat. Methods 9, 772 (2012).

78. Huelsenbeck, J. P. \& Ronquist, F. MRBAYES: Bayesian inference of phylogenetic trees. Bioinformatics 17, 754-755 (2001).

\title{
Acknowledgements
}

Angelika Lander, Ute Kramer, Ellen Richter, Arnt Ebinger, Jule Hinzmann, Jule Tesch, Merle Wegener, Georg Hille, Petra Kreher, Nicole Hetzelt for technical assistance, Berliner Artenschutz Team-BAT-e.V., F. Brandes, I. Frey-Mann, H. Geiger, J. Haensel, J. Harder, L. Ittermann, M. Kistler, M. Kredler, S. Morgenroth, E. Mühlbach, K. Müller, R. Pfeiffer, W. Rietschel, S. Rosenau, R. Straub, G. Strauß, and W. and H. Zoels for providing the bat carcasses, Linfa Wang, Ina Smith and Gary Crameri for providing PaKi cells. We are also grateful to Ursula Erikli for copy-editing.

\section{Author contributions}

Conception and design of the project: C.K., K.M., G.W., A.K. Performing of experiments: C.K., A.B., A.R., K.M., G.W., A.K. Analysis and interpretation of research data: C.K., A.B., A.R., P.W.D., K.M., A.N., G.W., A.K. Drafting or critically revising significant parts of the work: C.K., A.B., A.R., P.W.D., K.M., A.N., G.W., A.K.

\section{Funding}

Open Access funding enabled and organized by Projekt DEAL.

\section{Competing interests}

The authors declare no competing interests.

Additional information

Supplementary Information The online version contains supplementary material available at https://doi.org/ 10.1038/s41598-021-86435-4.

Correspondence and requests for materials should be addressed to C.K.

Reprints and permissions information is available at www.nature.com/reprints.

Publisher's note Springer Nature remains neutral with regard to jurisdictional claims in published maps and institutional affiliations.

\begin{abstract}
Open Access This article is licensed under a Creative Commons Attribution 4.0 International License, which permits use, sharing, adaptation, distribution and reproduction in any medium or format, as long as you give appropriate credit to the original author(s) and the source, provide a link to the Creative Commons licence, and indicate if changes were made. The images or other third party material in this article are included in the article's Creative Commons licence, unless indicated otherwise in a credit line to the material. If material is not included in the article's Creative Commons licence and your intended use is not permitted by statutory regulation or exceeds the permitted use, you will need to obtain permission directly from the copyright holder. To view a copy of this licence, visit http://creativecommons.org/licenses/by/4.0/.
\end{abstract}

(c) The Author(s) 2021 